\title{
Impairment of mitochondrial calcium handling in a mtSOD I cell culture model of motoneuron disease
}

\author{
Manoj Kumar Jaiswal ${ }^{1}$, Wolf-Dieter Zech², Miriam Goos², \\ Christine Leutbecher ${ }^{1}$, Alberto Ferri ${ }^{3}$, Annette Zippelius ${ }^{5}$, \\ Maria Teresa Carrì ${ }^{3,4}$, Roland $\mathrm{Nau}^{2,6}$ and Bernhard U Keller*1
}

\begin{abstract}
Address: ${ }^{1}$ Center of Physiology, Georg-August University, Goettingen, Germany, ${ }^{2}$ Department of Neurology, Georg-August University, Goettingen Germany, ${ }^{3}$ Laboratory of Neurochemistry, Fondazione S. Lucia IRCCS, Rome, Italy, ${ }^{4}$ Department of Biology, University of Rome "Tor Vergata", Rome, Italy, ${ }^{5}$ Department of Physics, Georg-August University, Goettingen, Germany and ${ }^{6}$ Department of Geriatrics, Evangelisches Krakenhaus, Goettingen-Weende, Germany

Email: Manoj Kumar Jaiswal - manoj.jaiswal@medizin.uni-goettingen.de; Wolf-Dieter Zech - wolf.zech@web.de; Miriam Goos - mlotz@gwdg.de; Christine Leutbecher - drleutbecher@aventra.org; Alberto Ferri - a.ferri@hsantalucia.it; Annette Zippelius - annette@theorie.physik.uni-goettingen.de; Maria Teresa Carrì - carri@uniroma2.it; Roland Nau - rnau@gwdg.de; Bernhard U Keller* - bkeller1@gwdg.de

* Corresponding author
\end{abstract}

Published: 22 June 2009

BMC Neuroscience 2009, 10:64 doi:10.1186/147/-2202-10-64
Received: 3 April 2009

Accepted: 22 June 2009

This article is available from: http://www.biomedcentral.com/I47I-2202/I0/64

(C) 2009 Jaiswal et al; licensee BioMed Central Ltd.

This is an Open Access article distributed under the terms of the Creative Commons Attribution License (http://creativecommons.org/licenses/by/2.0), which permits unrestricted use, distribution, and reproduction in any medium, provided the original work is properly cited.

\begin{abstract}
Background: Amyotrophic lateral sclerosis (ALS) is a fatal neurodegenerative disorder characterized by the selective loss of motor neurons (MN) in the brain stem and spinal cord. Intracellular disruptions of cytosolic and mitochondrial calcium have been associated with selective $\mathrm{MN}$ degeneration, but the underlying mechanisms are not well understood. The present evidence supports a hypothesis that mitochondria are a target of mutant SODI-mediated toxicity in familial amyotrophic lateral sclerosis (fALS) and intracellular alterations of cytosolic and mitochondrial calcium might aggravate the course of this neurodegenerative disease. In this study, we used a fluorescence charged cool device (CCD) imaging system to separate and simultaneously monitor cytosolic and mitochondrial calcium concentrations in individual cells in an established cellular model of ALS.

Results: To gain insights into the molecular mechanisms of SODIG93A associated motor neuron disease, we simultaneously monitored cytosolic and mitochondrial calcium concentrations in individual cells. Voltage - dependent cytosolic $\mathrm{Ca}^{2+}$ elevations and mitochondria - controlled calcium release mechanisms were monitored after loading cells with fluorescent dyes fura-2 and rhod-2. Interestingly, comparable voltage-dependent cytosolic Ca ${ }^{2+}$ elevations in WT (SH-SY5YWT) and G93A (SH-SY5YG93A) expressing cells were observed. In contrast, mitochondrial intracellular $\mathrm{Ca}^{2+}$ release responses evoked by bath application of the mitochondrial toxin FCCP were significantly smaller in G93A expressing cells, suggesting impaired calcium stores. Pharmacological experiments further supported the concept that the presence of $\mathrm{G} 93 \mathrm{~A}$ severely disrupts mitochondrial $\mathrm{Ca}^{2+}$ regulation.

Conclusion: In this study, by fluorescence measurement of cytosolic calcium and using simultaneous $\left[\mathrm{Ca}^{2+}\right] \mathrm{i}$ and $\left[\mathrm{Ca}^{2+}\right]_{\text {mito }}$ measurements, we are able to separate and simultaneously monitor cytosolic and mitochondrial calcium concentrations in individual cells an established cellular model of ALS. The primary goals of this paper are (I) method development, and (2) screening for deficits in mutant cells on the single cell level. On the technological level, our method promises to serve as a valuable tool to identify mitochondrial and $\mathrm{Ca}^{2+}$-related defects during $\mathrm{G} 93 \mathrm{~A}$-mediated $\mathrm{MN}$ degeneration. In addition, our experiments support a model where a specialized interplay between cytosolic calcium profiles and mitochondrial mechanisms contribute to the selective degeneration of neurons in ALS.
\end{abstract}




\section{Background}

Amyotrophic lateral sclerosis (ALS) is a fatal neurodegenerative disorder characterized by a selective loss of motor neurons (MNs) in the brain stem, the spinal cord and the motor cortex, leading to progressive weakness, muscle atrophy with eventual paralysis, and death. Approximately $5-10 \%$ of ALS cases are familial $[1,2]$. A decade ago, researchers discovered missense mutations in the gene encoding the $\mathrm{Cu} / \mathrm{Zn}$ superoxide dismutase 1 (SOD1) in subsets of familial cases; approximately $20 \%$ of familial ALS (fALS) is caused by mutations in SOD1 with high inter-subject variation of progression, including the point mutation G93A [3-7]

Multiple cascades have been implicated in the motor neuron death pathway, including mitochondrial dysfunction and deformities [8-15]; complex I, III, and IV abnormalities [16-19]; mitochondrial alteration, increase in $\mathrm{Ca}^{2+}$ uptake and increase of cytosolic $\mathrm{Ca}^{2+}$ concentration $[6,20]$, oxidative stress [21]; and glutamate excitotoxicity [22-29]. Alteration and disruption of calcium homeostasis and metabolism [30-40] has also been reported.

The present evidence supports a hypothesis that mitochondrial dysfunction acts with oxidative stress to cause abnormal neurodegeneration via calcium-mediated $\mathrm{MN}$ injury. Oxidative stress may lead to increased intracellular calcium, which leads to increased nitric oxide and peroxynitrite formation [21]. Glutamate excitotoxicity may disrupt intracellular calcium homeostasis and reactive oxygen species (ROS) production [27], which may be promoted by oxidative stress as glutamate transporters are particularly susceptible to disruption by oxidants, and oxidative modifications to the transporter have been reported in ALS and the mtSOD1G93A mouse model $[24,21]$. The etiology is likely to be multifactorial because ALS involves the interplay of several mechanisms to initiate disease and propagate the spread of motor neuron cell death $[36,38,39]$.

Mitochondrial $\mathrm{Ca}^{2+}$ uptake responds dynamically and sensitively to changes in cytosolic $\mathrm{Ca}^{2+}$ levels and plays a crucial role in sequestering the large $\mathrm{Ca}^{2+}$ loads induced by FCCP-evoked $\mathrm{Ca}^{2+}$ influx [41]. The excessive influx of $\mathrm{Ca}^{2+}$ into mitochondria may result in mitochondrial dysfunction. Prominent and sustained mitochondrial depolarization follows intense ion channel receptor stimulation and closely parallels the incidence of neuronal death [42]. Substantial $\mathrm{Ca}^{2+}$ can be accumulated in mitochondria as a result of overloading the matrix with $\mathrm{Ca}^{2+}$; this disrupts the structural and functional integrity of the organelle. Hence, mitochondria may be a critical intracellular target of injury after intense $\mathrm{Ca}^{2+}$ channel stimulation and, in this way, may act as a link between massive $\mathrm{Ca}^{2+}$ influx and mitochondria-mediated neurotoxicity by
mtSOD1G93A. However, the precise relationship between $\mathrm{Ca}^{2+}$ influx, cytosolic $\mathrm{Ca}^{2+}$ increase, and mitochondrial $\mathrm{Ca}^{2+}$ uptake remains obscure.

Culture systems, such as slice culture or primary cultures of $\mathrm{MN}$, have proven to be valuable tools in the physiological and biochemical characterization of ALS-related pathology [43-45]. Still unknown is whether the presence of mtSOD1 ${ }^{\mathrm{G} 93 \mathrm{~A}}$ causes morphological mitochondrial abnormalities when expressed at physiological levels, whether the source specificity of mitochondrial $\mathrm{Ca}^{2+}$ sequestration and spatiotemporal properties of cytosolic $\mathrm{Ca}^{2+}\left(\left[\mathrm{Ca}^{2+}\right] \mathrm{i}\right)$ signaling in cells transfected with wild-type and G93A-mutant SOD1 varies at physiological levels, and if there are functional consequences of changes in mitochondrial function on $\mathrm{Ca}^{2+}$ homeostasis in the presence of mtSOD1G93A. To elucidate the underlying molecular events and cellular alterations involved in oxidative stress induced by the aberrant $\mathrm{Cu}-\mathrm{Zn}$ chemistry and the roles of impaired $\mathrm{Ca}^{2+}$ handling and oxidative stress induced by ROS in FALS, we used SH-SY5Y neuroblastoma cells transfected with the G93A mutant form of SOD1 typical for fALS (SH-SY5YG93A or G93A) and SH-SY5Y cells transfected with wild-type (WT) human SOD1 (SHSY5YWT or WT) and mimic the situation present in heterozygous patients, previously established as an in-vitro cell culture model of ALS, resembling the situation of heterozygous patients $[6,46]$. This particular mutation was chosen because it does not affect the activity of SOD1; previously it was shown that SH-SY5Y cells expressing G93A exhibit increased intracellular ROS [47]. The effect of the continuous expression of WT or G93A on mitochondrial morphology and $\mathrm{Ca}^{2+}$ signaling were compared. In addition, the consequences and impact of protonophore FCCP and other organelle-specific drugs on mitochondrial vulnerability and $\mathrm{Ca}^{2+}$ homeostasis were studied.

\section{Methods \\ SH-SY5YWT and SH-SY5YG93A transfected neuroblastoma cell cultures}

An in-vitro model to study the cellular alterations associated with mutations of SOD1 was constructed by transfection of the human neuroblastoma cell line SH-SY5Y with G93A-SOD1 [6]. The cell types that we have used in our study are well characterized and have been used as cellular model system for motoneuron disease by several groups [6,48-50]. The transfected cell lines have relatively low levels of $\mathrm{mtSOD} / \mathrm{wtSOD}$ and are therefore an attractive model system for the human disease [50]. Upon expression of fALS - SOD1, these cells show several features typical of neurons of both ALS patients and transgenic mice, such as mitochondrial alteration, increased ROS levels and increased cytosolic calcium concentration [see references in [49]]. 
Transfected human neuroblastoma cell lines constitutively expressing either WT human SOD1 or the G93A mutant form of this enzyme associated with fALS were routinely maintained in Dulbecco's Modified Eagle Medium (DMEM)-F12 (Gibco, Invitrogen, Karlsruhe, Germany) containing 15\% fetal calf serum (FCS; Biochrom, Berlin, Germany), $100 \mathrm{U} / \mathrm{ml}$ penicillin (Biochrom, Berlin, Germany), and $100 \mu \mathrm{g} / \mathrm{ml}$ streptomycin (Gibco, Invitrogen, Karlsruhe, Germany) at $37^{\circ} \mathrm{C}$ in a humidified atmosphere with $5 \% \mathrm{CO}_{2}$ [6]. The cell lines were under consistent selection by addition of $200 \mu \mathrm{g} / \mathrm{ml}$ geneticin (G418 sulfate, Gibco, Invitrogen, Karlsruhe, Germany), which was removed two days before performing the experiments.

\section{Intracellular fluorometric $\mathbf{C a}^{2+}$ measurements}

The calcium-sensitive fluorescent dye, Fura-2, was introduced into cells by loading the membrane-permeable AMester forms $\left(5 \mu \mathrm{M}, 30 \mathrm{~min}, 37^{\circ} \mathrm{C}, 5 \% \mathrm{CO}_{2}\right.$ and $95 \% \mathrm{O}_{2}$ ), which is termed bolus loading. Fura-2 AM was purchased from Invitrogen (Carlsbad, CA, USA) and freshly dissolved in dimethyl sulfoxide (DMSO) containing $10 \%$ pluronic acid before the experiment. Changes in $\left[\mathrm{Ca}^{2+}\right] \mathrm{i}$ were measured in non-transfected SH-SY5Y cells (Parental cell line) and SH-SY5Y cells expressing WT or G93A attached to glass cover slips after 2-5 days in culture. Cell layers were incubated with RPMI-1640 (Biochrom, Berlin, Germany) containing 10\% FCS (Gibco, Invitrogen, Karlsruhe, Germany) and $0.846 \mathrm{mM} \mathrm{Ca}^{2+}$ (supplier's data). Cells were rinsed with RPMI -1640 and incubated for 20 min at $37^{\circ} \mathrm{C}$ to allow for complete de-esterification.

Changes in $\left[\mathrm{Ca}^{2+}\right] \mathrm{i}$ were monitored by the excitation of Fura-2 AM at $360 \mathrm{~nm}$ and $390 \mathrm{~nm}$; emitted light was directed to a dichroic mirror by a beam splitter at $425 \mathrm{~nm}$. In the case of non-transfected SH-SY5Y cells, the excitation of Fura-2 AM was performed at $356 \mathrm{~nm}$ and $385 \mathrm{~nm}$ and the emitted light was directed to a dichroic mirror with mid-reflection at $425 \mathrm{~nm}$. In some experiments, the light was filtered by a band pass filter of 505-530 nm [See Additional file 1]. Since the background fluorescence is not clearly determinable in AM loaded cells, we regarded the calculated $\mathrm{Ca}^{2+}$ concentrations as an approximation of the real concentration [19]. Therefore, for ester-loaded cells, changes in $\left[\mathrm{Ca}^{2+}\right] \mathrm{i}$ are given as changes in the Fura-2 ratio $(360 / 390 \mathrm{~nm})$.

Fura-2 $(\mathrm{Kd} \sim 0.2 \mu \mathrm{M})$ was monitored by a computer-controlled monochromator (Polychrome II, TILL Photonics, Germany), which was connected to an Axioscope microscope (Zeiss, Goettingen, Germany) via quartz fiber optics and a minimum number of optical components for maximum fluorescence excitation (objective Achroplan W $63 \mathrm{x}, 0.9 \mathrm{~W})$. The apparatus was equipped with a CCD camera system [51,52], which displayed 12-bit dynamics
(PCO, Germany), and an A/D converter with a $12.5 \mathrm{MHz}$ sampling rate; the binning was set to $4 \times 4$ and the exposure time was $30-80 \mathrm{~ms}$. Calcium changes in defined regions of interest (ROIs) were monitored online using TILL Vision Software V3.3 (TILL Photonics, Martinsried, Germany). The measured fluorescence ratio at the selected wavelengths was used to calculate the $\left[\mathrm{Ca}^{2+}\right] \mathrm{i}$ and was represented as F/F0. Further analysis was performed off-line with the IGOR software (Wavemetrics, Lake Oswego, OR, USA) and Origin software, version 7.5.

\section{Simultaneous recording of changes in $\left[\mathrm{Ca}^{2+}\right]$ i and $\left[\mathrm{Ca}^{2+}\right]$ mito}

Simultaneous fluorometric measurements of $\left[\mathrm{Ca}^{2+}\right] \mathrm{i}$ and

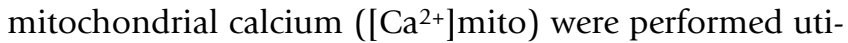
lizing calcium-sensitive fluorescent dyes (Fura-2 AM for cytosolic calcium and Rhod-2 AM for mitochondrial calcium). SH-SY5Y cells expressing either WT or G93A were attached to glass cover slips and loaded initially with $5 \mu \mathrm{M}$ Fura- $2 \mathrm{AM}$ at $37^{\circ} \mathrm{C}$ for $30 \mathrm{~min}$ as described above. Subsequently, cells were washed with RPMI-1640 for $20 \mathrm{~min}$ and further incubated with $10 \mu \mathrm{M}$ Rhod-2 AM for $20 \mathrm{~min}$ at $37^{\circ} \mathrm{C}\left(5 \% \mathrm{CO}_{2}\right.$ and $\left.95 \% \mathrm{O}_{2}\right)$. The coverslips were rinsed with RPMI-1640 and further incubated for $20 \mathrm{~min}$ at $37^{\circ} \mathrm{C}$ to allow for complete de-esterification.

To clearly separate and simultaneously monitor the dynamic $\left[\mathrm{Ca}^{2+}\right] \mathrm{i}$ and $\left[\mathrm{Ca}^{2+}\right]$ mito profiles with a temporal resolution in the millisecond time domain, we utilized a computer-controlled monochromator that rapidly switched between excitation wavelengths of $390 \mathrm{~nm}$ (Fura-2) and $550 \mathrm{~nm}$ (Rhod-2) and collected wavelengths above $565 \mathrm{~nm}$ for both excitation conditions. Schematic representation of the CCD-imaging setup used for conventional calcium imaging and simultaneous imaging of $\left[\mathrm{Ca}^{2+}\right] \mathrm{i}$ and $\left[\mathrm{Ca}^{2+}\right]$ mito signals in the cell line preparation are illustrated in Additional file 1 [See Additional file 1]. For kinetic data analysis, only Fura- 2 and Rhod- 2 signals from pre-defined regions of cells were used.

The accumulations of mitochondrial and other cell organelles calcium were inhibited by cell organelles specific drug modulators. First, drugs were used, including $\mathrm{KCl}\left(\mathrm{K}^{+}\right)$, depolarisation stimulus; FCCP, a protonophore; and oligomycin (oligo), a $\mathrm{F}_{1}, \mathrm{~F}_{0}$-ATPase blocker preventing maintenance of the proton gradient, which disrupt the mitochondrial membrane potential $\left(\Delta \Psi_{\mathrm{m}}\right)$ [53-56]. Secondly, by thapsigargin (thapsi) an extremely tight binding inhibitor of intracellular $\mathrm{Ca}^{2+}$ pumps, which raises cytosolic calcium concentration by blocking the ability of the cell to pump calcium into the sarcoplasmic and endoplasmic reticulum which causes these stores to become depleted [57]. Store-depletion can secondarily activate plasma membrane calcium channels, allowing an influx of calcium into the cytosol. Thirdly, by caffeine, a specific 
activator of $\mathrm{Ca}^{2+}$ influx from ryanodine receptor (RyR)dependent $\mathrm{Ca}^{2+}$ stores [58].

\section{Statistical analysis}

Each cover slip was used for a single experiment and included more than 4 cells for each imaging experiment. Unless otherwise indicated, values in the text are given as mean \pm standard deviation (SD) and the error bars indicate SD too. All values represent at least three separate experiments. Significance was calculated using the two tailed unpaired Student t-test. A $p$-value $<0.05$ was consider statistically significant. Five point smoothing was performed in the case of simultaneous $\left[\mathrm{Ca}^{2+}\right] \mathrm{i}$ and $\left[\mathrm{Ca}^{2+}\right]$ mito signals to remove the noise.

\section{Chemical induction of calcium release}

Carbonyl cyanide p-(trifluoromethoxy) phenylhydrazone (FCCP), thapsigargin, and oligomycin were purchased from Sigma-Aldrich Chemie (Deisenhoff, Germany). FCCP was bath applied at a dose of $2 \mu \mathrm{M}$. A comparative analysis of the $\mathrm{Ca}^{2+}$ influx in WT and G93A transfected cells was done in the presence of FCCP. For these experiments the SH-SY5Y cells were loaded with $5 \mu \mathrm{M}$ Fura-2 AM through the incubation method and $\left[\mathrm{Ca}^{2+}\right] \mathrm{i}$ transients were triggered once Fura-2 AM concentration was equilibrated after washing. $\mathrm{Ca}^{2+}$ release from intracellular stores by inhibition of the sarcoplasmic/endoplasmic reticulm $\mathrm{Ca}^{2+}$-dependent ATPase pump and inhibition of $\mathrm{F}_{1}, \mathrm{~F}_{0^{-}}$ ATP Synthase was done by intervention of thapsi, and oligo, respectively.

For the investigation of endoplasmic reticulum (ER)dependent $\mathrm{Ca}^{2+}$ release, caffeine has been established as a specific activator of $\mathrm{Ca}^{2+}$ influx from the RyR-dependent $\mathrm{Ca}^{2+}$ stores [58]. To investigate the relative impact of the ER and mitochondria in $\left[\mathrm{Ca}^{2+}\right] \mathrm{i}$ regulation together with the association on MN degeneration in G93A transfected SH-SY5Y cells, we used pharmacological agents as a specific activator of the ER-dependent $\mathrm{Ca}^{2+}$ release response [59], which not only selectively blocks $\mathrm{Ca}^{2+}$ uptake into $\mathrm{ER} /$ mitochondrial compartments but also triggers $\mathrm{Ca}^{2+}$ release from intracellular storage sites. Caffeine was purchased from Sigma-Aldrich chemie (Deisenhofen, Germany) and dissolved in water $(25 \mathrm{mM})$. It was then diluted to the final concentration immediately before the experiment. We utilized $\mathrm{KCl}\left(\mathrm{K}^{+}\right)$concentrations of 30 $\mathrm{mM}$ for depolarisation induced $\mathrm{Ca}^{2+}$ transients.

\section{Results \\ Impaired mitochondrial responses of cytosolic calcium in G93A transfected cells}

Representative non-transfected SH-SY5Y neuroblastoma cells (parental cell line) stained with Fura-2 AM are shown in Additional file 2 [See Additional file 2]. Mitochondrial $\mathrm{Ca}^{2+}$ release responses were measured to verify the impact of mitochondrial uncoupler FCCP in normal SH-SY5Y cells. The application of FCCP for 2 min fairly inhibited mitochondrial $\mathrm{Ca}^{2+}$ and most of the cells had a proper distinguishable and characteristic fluorescence response (See Additional file 2]. In the cells matching set criteria, including a normal morphological appearance of a large soma and intense proper staining, we performed $\mathrm{Ca}^{2+}$ imaging 2-5 days after culture from WT-SOD1 and G93A transfected SH-SY5Y cells.

The transfected cells were treated with FCCP ( $3 \mathrm{~min}$ ) and the $\left[\mathrm{Ca}^{2+}\right] \mathrm{i}$ measured for both WT and G93A-transfected SH-SY5Y cells (Fig. 1). A CCD imaging photomicrograph series of $\left[\mathrm{Ca}^{2+}\right]$ i in $7-8$ cells before drug application (0.0s), after peak FCCP challenge ( $3 \mathrm{~min}$ ), and after FCCP wash in WT-SOD1 (a-c) and G93A (d-f) transfected cells are shown in Fig. 1A. Figs. $1 \mathrm{~B}$ and $1 \mathrm{C}$ show $\left[\mathrm{Ca}^{2+}\right] \mathrm{i}$ as cytoplasmic calcium versus time curves in 6 representative cells during FCCP challenge. The mitochondrial uncoupler induces a fast transient elevation in $\left[\mathrm{Ca}^{2+}\right] \mathrm{i}$ and a fast recovery to baseline in WT transfected cells (Fig. 1B, F/F0 $=0.1766 \pm 0.0362 ; \mathrm{N}=3, \mathrm{n}=17)$. The G93A transfected cells had a comparatively lower fluorescence intensity for transient elevation in $\left[\mathrm{Ca}^{2+}\right] \mathrm{i}$ followed by a delayed recovery to baseline (Fig. 1C, F/F0 = $0.0948 \pm 0.0223 ; \mathrm{N}=5, \mathrm{n}$ $=23$ ). The FCCP-induced calcium influx peak fluorescence intensity in G93A transfected cells was diminished by approximately $48 \%$ compared to the calcium influx peak fluorescence intensity of WT transfected cells (Fig. $1 \mathrm{D} ; p<0.001)$.

Calcium uptake by the mitochondria is accomplished by the mitochondrial calcium uniporter (MCU) located in the inner mitochondrial membrane [60]. The accumulation of mitochondrial $\mathrm{Ca}^{2+}$ may have a perceptible influence on the existence of a $\left[\mathrm{Ca}^{2+}\right] \mathrm{i}$ transient. This effect was studied by following the $\mathrm{Ca}^{2+}$ signal under healthy and deleterious mitochondrial conditions in the presence of FCPP. We found that, in G93A transfected SH-SY5Y cells, the $\mathrm{Ca}^{2+}$ influx (peak fluorescence) was diminished compared to WT transfected SH-SY5Y cells, which, peaked within 2-3 min and was followed by a baseline recovery in approximately $2 \mathrm{~min}$. The G93A transfected cells took almost 5-6 min to achieve a baseline recovery. However, the cells transfected with G93A suffered from reduced $\left[\mathrm{Ca}^{2+}\right]$ mito after depletion of mitochondrial $\mathrm{Ca}^{2+}$ stores by FCCP (Fig. 1).

\section{Effect of high $\mathrm{K}^{+}$-evoked $\mathrm{Ca}^{2+}$ transient and its impact on FCCP-induced $\mathrm{Ca}^{2+}$ influx}

To analyze the comparative efficiency of mitochondria as $\mathrm{a} \mathrm{Ca}^{2+}$ sequestering organelle, FCCP was applied to evacuate mitochondrial $\mathrm{Ca}^{2+}$ after the WT and G93A transfected cells had been exposed to an evoked $\mathrm{Ca}^{2+}$ load through a depolarizing stimulus of $\mathrm{K}^{+}$. First, the SH-SY5Y cells transfected with WT or G93A were stained with Fura-2 AM and exposed to $30 \mathrm{mM} \mathrm{K}+$ for $30 \mathrm{sec}$, which was followed by a 

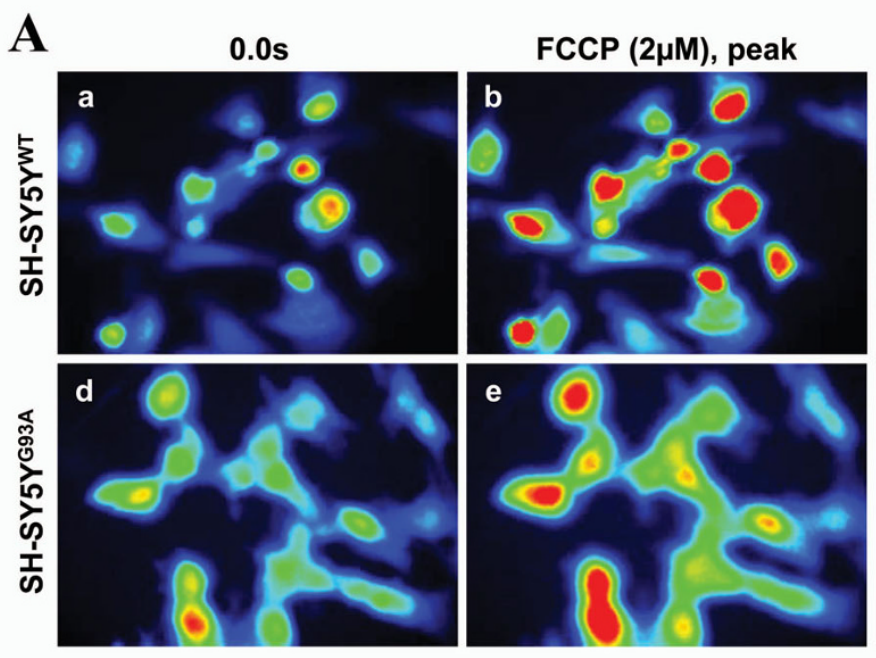

B

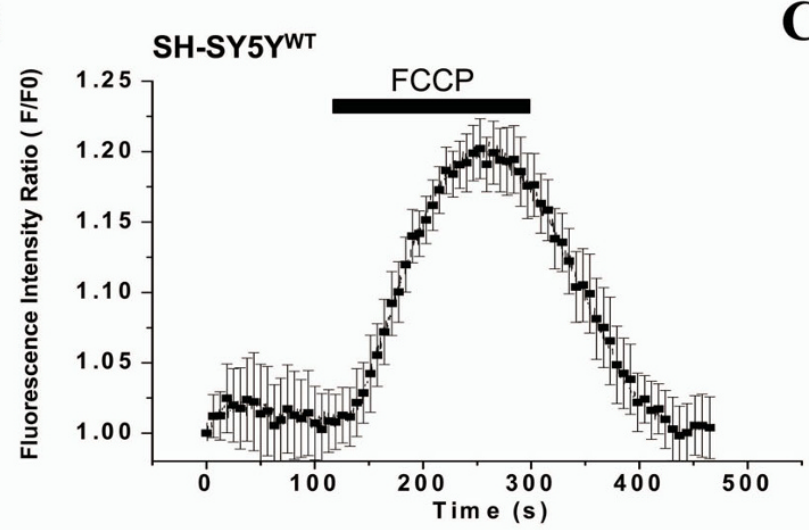

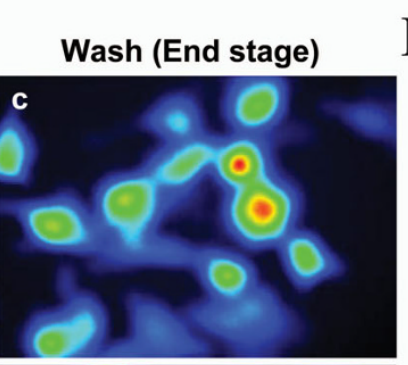

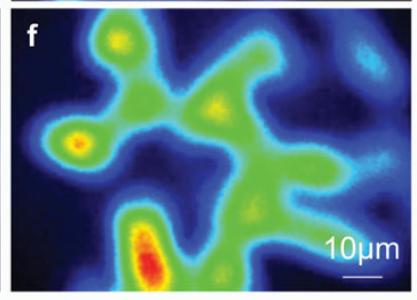

C

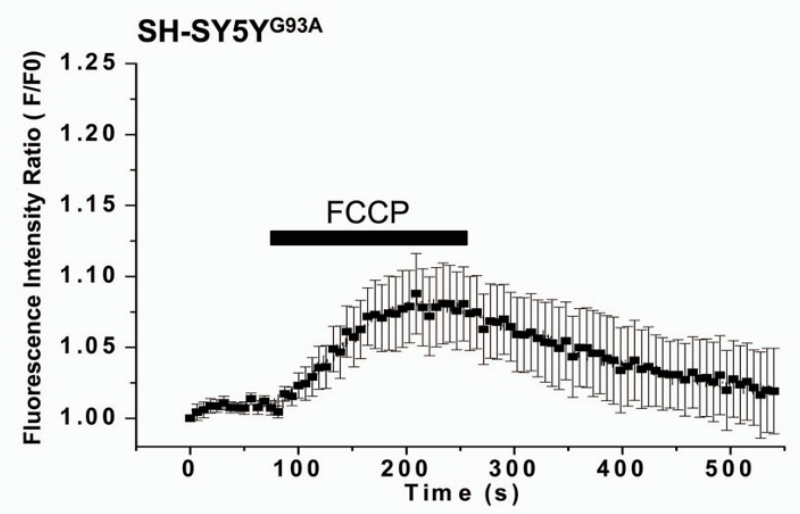

Figure I

FCCP induced mitochondrial depolarization in SH-SY5Y neuroblastoma cells transfected with G93A exhibits reduced peak fluorescence amplitude. A) A CCD imaging photomicrograph series showing [Ca $\left.{ }^{2+}\right]$ in 7-8 cells before drug application (0.0s), after peak $2 \mu$ M FCCP challenge for 3 min, and after FCCP wash in WT (a-c) and G93A (d-f) transfected $\mathrm{SH}-\mathrm{SY} 5 Y$ neuroblastoma cells. B) A representative figure of $\left[\mathrm{Ca}^{2+}\right]$ i fluorescence intensity in $6 \mathrm{SH}-\mathrm{SY} 5 Y$ neuroblastoma cells transfected with WT after FCCP application. FCCP $(2 \mu \mathrm{M})$ induced a fast, transient elevation in $\left[\mathrm{Ca}^{2+}\right]$ i and a fast recovery to baseline. C) In G93A transfected SH-SY5Y neuroblastoma cells, FCCP induced a transient elevation in [Ca ${ }^{2+}$ ]i fluorescence intensity that was lower in magnitude, followed by a plateau for I min, and a delayed recovery to baseline. D) A bar diagram to illustrate the reduction of the sustained $\mathrm{Ca}^{2+}$ response in G93A transfected SH-SY5Y neuroblastoma cells (F/F0 $=0.0948 \pm$ 0.0223; $N=5, n=23$ ) compared to WT transfected SH-SY5Y cells (F/F0 = 0.1766 $\pm 0.0362 ; N=3, n=17)$. Values represent means $\pm S D, *^{*} p<0.00$ I, scale bar $=10 \mu \mathrm{m}$. $\mathrm{N}=$ Number of experiments; $\mathrm{n}=$ Number of cells.

3 min challenge with FCCP (Fig. 2). As shown in Figs. 2A and $2 \mathrm{~B}$, the peak amplitude of FCCP-evoked $\mathrm{Ca}^{2+}$ influx after depolarization was $0.2440 \pm 0.0696(\mathrm{~N}=3, \mathrm{n}=20)$ and $0.1497 \pm 0.0362(\mathrm{~N}=5, \mathrm{n}=20)$ for the $\mathrm{WT}$ and G93A transfected cells, respectively. Fig. 2C shows the comparative analysis of average calcium release.

\section{Interaction between ER/mitochondria in differential $\mathrm{Ca}^{2+}$} store regulation by inhibition of the sarcoplasmicl endoplasmic reticulm $\mathrm{Ca}^{2+}$-dependent ATPase pump after pharamacological intervention

The relationships between mitochondrial calcium pools and those discharged by the $\mathrm{Ca}^{2+-A T P a s e}$ inhibitor thapsi, an extremely tight-binding inhibitor of intracellular $\mathrm{Ca}^{2+}$ pumps which induces rapid $\mathrm{Ca}^{2+}$ release from intracellular stores by inhibition of the sarcoplasmic/endoplasmic reticulm $\mathrm{Ca}^{2+}$-dependent ATPase pump without inositol phosphate formation $[57,61]$ were studied in WT and G93A transfected SH-SY5Y cells to estimate reciprocal functional interplay between the ER and mitochondria. It was previously shown in SOD1 G93A mice that release of ER based $\mathrm{Ca}^{2+}$ stores play minimal role and not an essential factors in the death mechanism of ALS vulnerbale MNs [62]. However, contrary to this study it was also shown that $\mathrm{Ca}^{2+}$ release from the ER contributes to neuronal cell death because the $\mathrm{Ca}^{2+}$ release blocker, dantrolene, can 

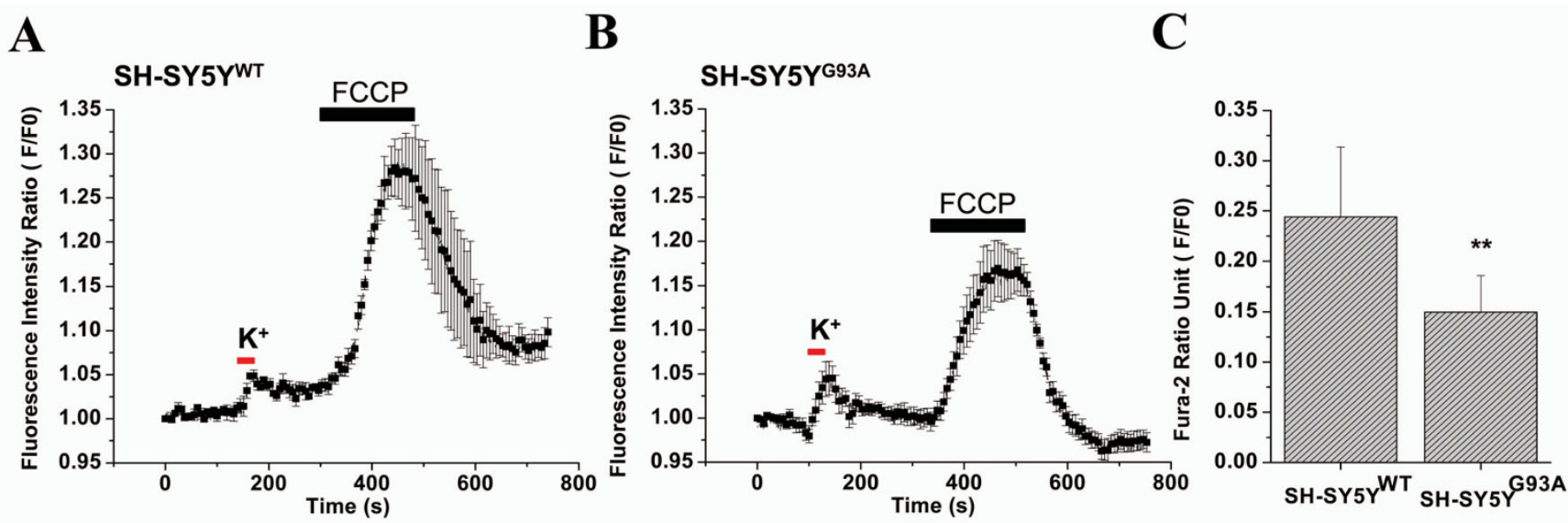

Figure 2

The effect of high $\mathrm{K}^{+}(30 \mathrm{mM})$ - evoked $\mathrm{Ca}^{2+}$ transient and its impact on the FCCP-induced Ca ${ }^{2+}$ influx in WT and G93A transfected SH-SY5Y neuroblastoma cells. A) A representative figure showing effect of perturbing the mitochondrial $\mathrm{Ca}^{2+}$ uptake on the calcium transient evoked by $30 \mathrm{mM} \mathrm{K}+$ depolarizing stimulus for 30 s (red horizontal bar) and by 2 $\mu \mathrm{M}$ FCCP-evoked $\mathrm{Ca}^{2+}$ efflux (black horizontal bar). FCCP $(2 \mu \mathrm{M})$ induced a fast, transient elevation in [Ca $\left.{ }^{2+}\right]$ i and a fast recovery to baseline after depolarization-induced stimulus in $7 \mathrm{SH}-\mathrm{SY} 5 Y$ cells transfected with WT. B) In G93A transfected SH-SY5Y cells, the FCCP-induced $\left[\mathrm{Ca}^{2+}\right]$ i transient elevation after depolarization-induced stimulus was delayed 5-10s and there was a reduction in the magnitude of fluorescence intensity followed by complete recovery to baseline. C) A bar diagram to illustrate the reduction of the sustained $\mathrm{Ca}^{2+}$ response in G93A transfected $\mathrm{SH}-\mathrm{SY} 5 \mathrm{Y}$ neuroblastoma cells $(\mathrm{F} / \mathrm{FO}=0.1497 \pm 0.0362 ; \mathrm{N}=$ $5, n=20$ ) compared to WT transfected SH-SY5Y cells (F/FO $=0.2440 \pm 0.0696 ; N=3, n=20)$. Values represent means \pm SD, $*_{*}{ }_{p}<0.00 \mathrm{I}$, scale bar $=20 \mu \mathrm{m} . \mathrm{N}=$ Number of experiments; $\mathrm{n}=$ Number of cells.

protect neurons against bioenergetic failure and cellular damage [63]. While little is known about the exact ER/ mitochondrial $\mathrm{Ca}^{2+}$ regulation mechanism in WT and G93A transfected cells, the restoration of ER function or attenuation of the secondary dysfunction induced by ER could present a new, highly promising mechansim for pharmacological intervention which could bring new ways to treat or minimize neuronal cell injury in the pathological states of ALS.

Analysis of the $\mathrm{Ca}^{2+}$ storing ability of ER and mitochondria in WT and G93A transfected cells was done using thapsi and FCCP. We show here that in fura-2-loaded cells, thapsi stimulated a slow plateau phase increase in cytoplasmic $\mathrm{Ca}^{2+}$ concentration in WT and G93A transfected cells. There was a significant quantitative difference between the ER and mitochondrial $\mathrm{Ca}^{2+}$ load in WT and G93A transfected cells; the $\mathrm{Ca}^{2+}$ release response was high in the mitochondria of WT transfected cells. As shown in Fig. 3, the peak amplitude of mitochondrial $\mathrm{Ca}^{2+}$ release after application of FCCP plus thapsi was $0.2712 \pm 0.0971$ and $0.1276 \pm 0.0287$ where as peak amplitude of $\mathrm{ER} \mathrm{Ca}^{2+}$ release after application of thapsi was $0.0412 \pm 0.0152$ and $0.02589 \pm 0.0137$ in WT and G93A transfected cells, respectively (Figs. $3 \mathrm{~A}-\mathrm{C}$ ). The impact of thapsi on the peak amplitude of $\mathrm{Ca}^{2+}$ release was nominal compared with FCCP, indicating a lesser role for ER compared with mitochondria in $\mathrm{Ca}^{2+}$ regulation. Comparative details of the normalized fura- 2 ratio in both WT and G93A transfected cells are summarized in Fig. $3 \mathrm{C}(\mathrm{N}=3, \mathrm{n}=15)$.

Interaction of ER/Mitochondria calcium stores regulation by activation of $\mathrm{Ca}^{2+}$ influx from the RyR-dependent $\mathrm{Ca}^{2+}$ stores

As shown in Fig. 4, caffeine led to a relatively slow and weak increase in the $\left[\mathrm{Ca}^{2+}\right]$ i fluorescence signals, which was very similar for both WT and G93A transfected cells $(\mathrm{N}=3, \mathrm{n}=14)$. We found that WT transfected cells (Figs. $4 \mathrm{~A}$ and $4 \mathrm{C}$ ) were affected by $5 \mathrm{mM}$ caffeine with a small and slow increase in $\left[\mathrm{Ca}^{2+}\right] \mathrm{i}(\mathrm{F} / \mathrm{F} 0=0.0471 \pm 0.0190)$ and exhibited slightly higher kinetics than the G93A transfected cells $\left(\left[\mathrm{Ca}^{2+}\right] \mathrm{i}: \mathrm{F} / \mathrm{FO}=0.0353 \pm 0.0120\right.$; Figs. $4 \mathrm{~B}$ and 4C). This suggests that the caffeine-evoked ER-dependent $\mathrm{Ca}^{2+}$ release either makes only a minor contribution to mitochondrial mediated toxicity in G93A transfected cells, as reported in other cell types and animal models, or occurs upstream of the mitochondria.

The cells were treated with FCCP in the presence of caffeine, which resulted in the depolarization of the mitochondria (Fig. 4). We observed a rapid and high amplitude increase of $\left[\mathrm{Ca}^{2+}\right] \mathrm{i}$, which exhibited a very distinct and differential response for WT and G93A transfected cells $(N=3, N=14)$. WT transfected cells revealed that caffeine and FCCP together evoked a massive and comparatively fast increase in the Fura-2 fluorescence sig- 

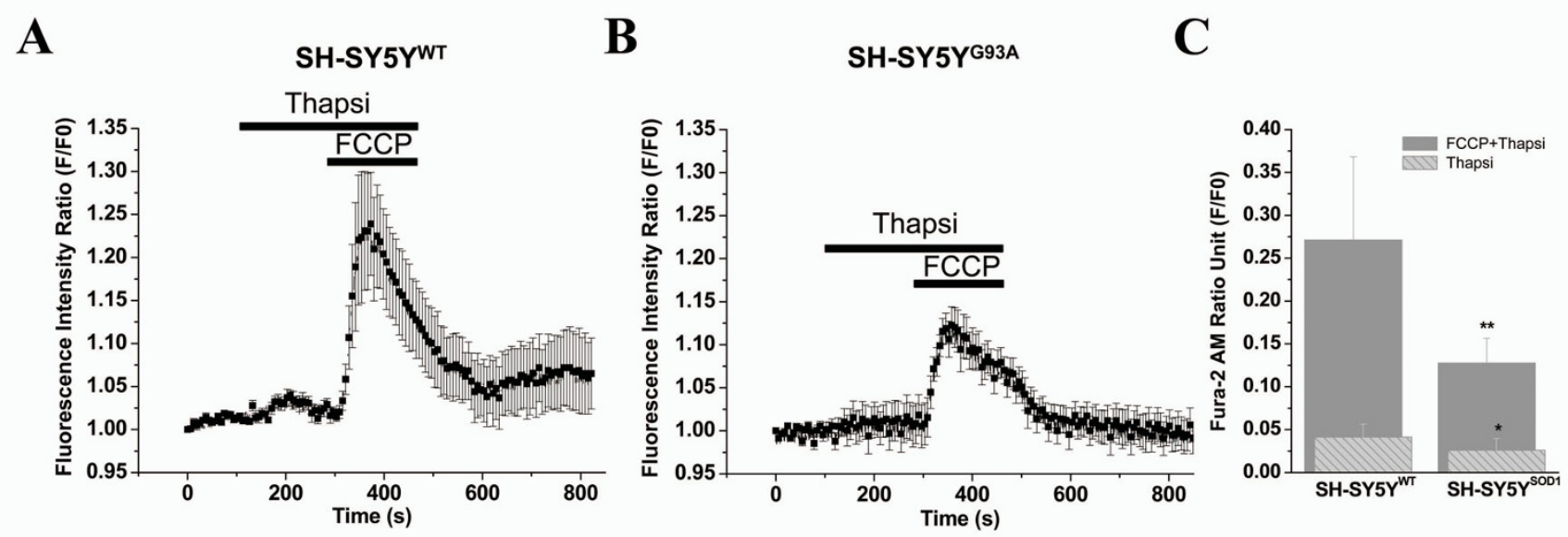

Figure 3

Analysis of the differential $\mathrm{Ca}^{2+}$ storage and regulation of the ER and mitochondria by pharmacological intervention in WT and G93A transfected SH-SY5Y cells. Cells were stimulated using thapsi and FCCP, which interfere with the integrity of the ER and mitochondria, respectively, and were used to release $\mathrm{Ca}^{2+}$ from intracellular stores by inhibition of the sarcoplasmic/endoplasmic reticulm $\mathrm{Ca}^{2+}$-dependent ATPase pump and mitochondrial stores by protonophore action. A) The quantitative kinetic profile of the thapsi and FCCP-evoked [ $\left.\mathrm{Ca}^{2+}\right]$ i release in WT transfected SH-SY5Y cells. B) The corresponding quantitative kinetic profile of the thapsi and FCCP-evoked [ $\left.\mathrm{Ca}^{2+}\right]$ i release in the G93A transfected SH-SY5Y cells. The trace is representative of mean of 4-6 cells in focus stimulated with thapsi $(5 \mu \mathrm{g} / \mathrm{ml} ; 6 \mathrm{~min})$ and $2 \mu \mathrm{M}$ FCCP ( $3 \mathrm{~min}$, normalized data). The horizontal black bars indicate the duration of stimulation by thapsi and with FCCP plus thapsi. Fura-2 AM signals are represented as F/FO. C) A bar diagram of thapsi and FCCP plus thapsi-induced $\mathrm{Ca}^{2+}$ release in the WT and G93A transfected SH-SY5Y neuroblastoma cells $(N=3, n=15)$. Gray bars represent thapsi plus FCCP-induced $\mathrm{Ca}^{2+}$ release in WT $(\mathrm{F} / \mathrm{FO}=$ $0.27 / 2 \pm 0.097 \mathrm{I})$ and $\mathrm{G} 93 \mathrm{~A}(\mathrm{~F} / \mathrm{FO}=0.1276 \pm 0.0287)$ transfected SH-SY5Y cells. Striped bars represent thapsi-induced $\mathrm{Ca}^{2+}$ release in WT (F/FO $=0.0412 \pm 0.0152)$ and $\mathrm{G} 93 \mathrm{~A}(\mathrm{~F} / \mathrm{FO}=0.0258 \pm 0.0137)$ transfected cells. Values represent means $\pm S D, * p$ $<0.01,{ }^{* *} p<0.001$. $\mathrm{N}=$ Number of experiments; $\mathrm{n}=$ Number of cells.

nals for WT $(\mathrm{F} / \mathrm{F} 0=0.1883 \pm 0.0584$, Figs. $4 \mathrm{~A}$ and $4 \mathrm{C})$ and G93A transfected cells $(\mathrm{F} / \mathrm{FO}=0.1154 \pm 0.0246$, Figs. 4B and $4 \mathrm{C})$.

\section{Manipulation of mitochondria in WT and G93A transfected SH-SY5Y cells by pharmacological Inhibition of $F_{1}, F_{0}$-ATP Synthase}

As an uncoupler of mitochondria, FCCP collapses the mitochondrial membrane potential. In turn, this results in a rapid release of calcium from this store and a slower drop in ATP levels [64]. Impairment of the mitochondria with FCCP may block oxidative phosphorylation and has the potential to compromise oxidative phosphorylation; in this state, glycolysis provides the prime means of ATP synthesis. Previously, evidence had suggested that ATP depletion by FCCP in MNs leads to minimal effect on reverse cycle of uncoupling of oxidative phosphorylation ([62], S. Balakrishnan and B.U. Keller, unpublish data). We assume that the sole effect of FCCP on cells is the uncoupling of mitochondria and that this results might lead to a reduction of the proton gradient across the internal mitochondrial membrane. Oligo, an ATP synthase inhibitor, also depletes ATP but does not alter mitochondrial membrane potential and thus does not change calcium transport across the mitochondrial membrane.
Oligo was added with FCCP to prevent any accelerated consumption of cellular ATP by the reverse mode of ATP synthase operation $[65,66]$.

To clarify this issue, we measure the impact of oligo $(5 \mu \mathrm{g} /$ $\mathrm{ml}$ ) on FCCP-induced $\mathrm{Ca}^{2+}$ release in WT and G93A transfected SH-SY5Y cells loaded with fura-2. Very weak effects to those previously observed with the electron transport inhibitors $\left(\mathrm{CN}^{-}\right)$and azide were seen with oligomycin $[19,62]$. As shown in Figs. 5A-C, impact of oligo's on the normalized peak fluorescence of fura- 2 was $0.0454 \pm$ 0.0175 and $0.0229 \pm 0.0161$ for WT and G93A transfected SH-SY5Y cells, respectively (Fig. 5C). The impact of oligomycin on the peak amplitude of fura-2 fluorescence was nominal and there was slight difference between WT and G93A transfected SH-SY5Y cells. However, the response to FCCP plus oligomycin in WT transfected cells (Fig. 5C) was almost 2.71-fold higher $(\mathrm{F} / \mathrm{F} 0=0.2245 \pm 0.0727)$ compared with G93A transfected SH-SY5Y cells $(\mathrm{F} / \mathrm{FO}=$ $0.0827 \pm 0.0304$; Figs. 5A-C).

\section{Simultaneous measurement of $\left[\mathrm{Ca}^{2+}\right]$ i and $\left[\mathrm{Ca}^{2+}\right]$ mito}

Using FCCP to prevent a $\left[\mathrm{Ca}^{2+}\right]$ mito increase while measuring an increase in $\left[\mathrm{Ca}^{2+}\right] \mathrm{i}$, we were able to efficiently separate cytosolic and mitochondrial $\mathrm{Ca}^{2+}$ at a temporal 


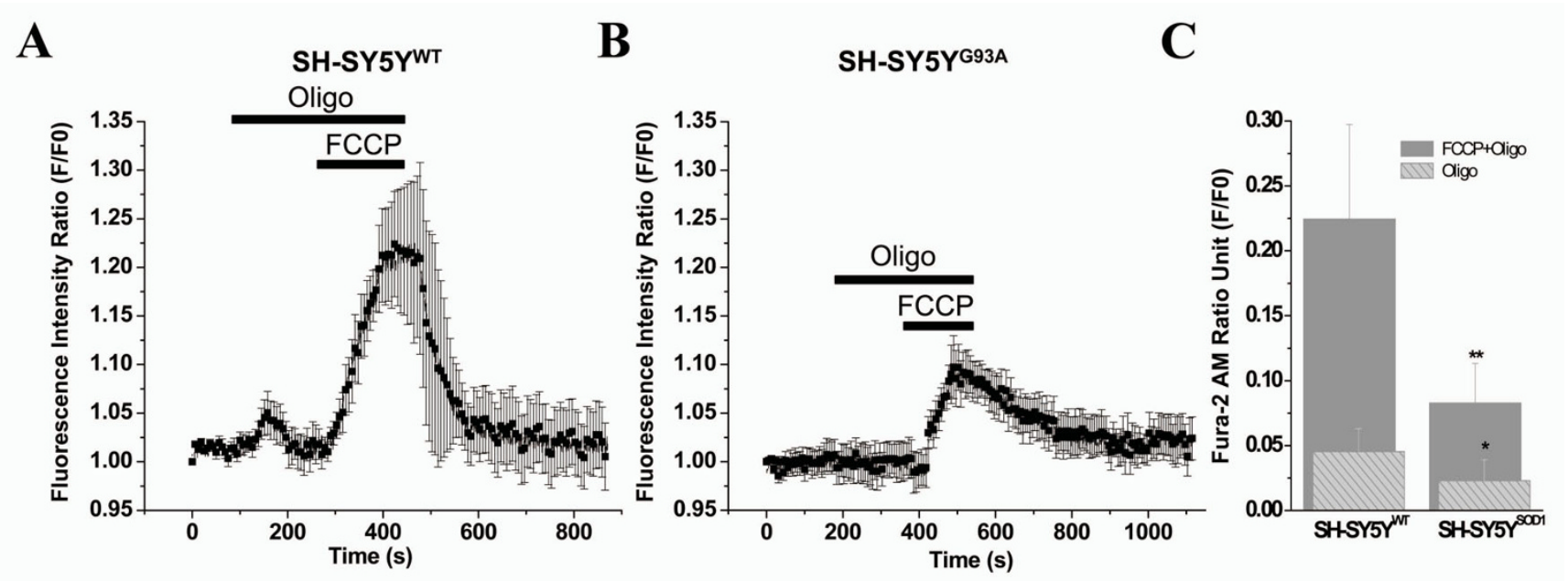

\section{Figure 4}

Impact of inhibition of FI, F0-ATP synthase on FCCP-evoked responses of [Ca $\left.{ }^{2+}\right]$ i in WT and G93A transfected SH-SY5Y cells. A) The quantitative kinetic profile of the oligo and FCCP-evoked $\left[\mathrm{Ca}^{2+}\right]$ i release in WT transfected SH-SY5Y cells. B) The corresponding quantitative kinetic profile of the oligo and FCCP-evoked [Ca2+]i release in the G93A transfected SH-SY5Y cells. The trace is representative of mean of 4-6 cells in focus stimulated with oligo (5 $\mu$ g/ml; $6 \mathrm{~min})$ and $2 \mu$ M FCCP ( 3 min, normalized data). The horizontal black bars indicate the duration of stimulation by oligo and with FCCP plus oligo. Fura-2 AM signals are represented as F/FO. C) A bar diagram of oligo and FCCP plus oligo-induced $\mathrm{Ca}^{2+}$ release in the WT $(\mathrm{N}=3, n=20)$ and G93A $(\mathrm{N}=3, \mathrm{n}=19)$ transfected SH-SY5Y neuroblastoma cells. Gray bars represent oligo plus FCCPinduced $\mathrm{Ca}^{2+}$ release in WT (F/FO $\left.=0.2245 \pm 0.0727\right)$ and G93A (F/FO $\left.=0.0827 \pm 0.0304\right)$ transfected SH-SY5Y cells. Striped bars represent oligo-induced $\mathrm{Ca}^{2+}$ release in $\mathrm{WT}(\mathrm{F} / \mathrm{FO}=0.0454 \pm 0.0 \mathrm{I} 75)$ and $\mathrm{G} 93 \mathrm{~A}(\mathrm{~F} / \mathrm{FO}=0.0229 \pm 0.0 \mathrm{I} 6 \mathrm{I})$ transfected cells. Values represent means $\pm S D, * p<0.01$, ${ }^{*} p<<0.001$. $N=$ Number of experiments; $n=$ Number of cells.

resolution in the millisecond time domain. As shown in Fig. 1, the $\mathrm{Ca}^{2+}$ release in G93A transfected cells is smaller in amplitude and exhibits slower kinetics compared to WT transfected cells. To confirm that there are separate $\mathrm{Ca}^{2+}$ uptake and release events from the cytosol and mitochondria, the transfected cells were treated with FCCP and the separate $\mathrm{Ca}^{2+}$ levels measured simultaneously (Fig. 6). WT transfected cells exhibited a substantial increase in $\left[\mathrm{Ca}^{2+}\right] \mathrm{i}$ $(\mathrm{F} / \mathrm{FO}=0.1569 \pm 0.0235 ;$ Fig. $6 \mathrm{~A}, \mathrm{~N}=5 ; \mathrm{n}=17)$ while $\left[\mathrm{Ca}^{2+}\right]$ mito decreased $(\mathrm{F} / \mathrm{F} 0=-0.1069 \pm 0.0181$, Fig. 6A, N $=5 ; \mathrm{n}=17)$. This suggests that the FCCP-evoked increase in $\left[\mathrm{Ca}^{2+}\right] \mathrm{i}$ in Fig. 1 was mainly due to $\left[\mathrm{Ca}^{2+}\right] \mathrm{i}$ and that there was very little impact from $\left[\mathrm{Ca}^{2+}\right]$ mito. In G93A transfected cells, FCCP-evoked [ $\left.\mathrm{Ca}^{2+}\right] \mathrm{i}$ was less and exhibited slower kinetics $(\mathrm{F} / \mathrm{FO}=0.1008 \pm 0.0248$; Figs. $6 \mathrm{~B}$ and $6 \mathrm{C}, \mathrm{N}=4 ; \mathrm{n}=17$ ) compared to WT transfected cells, which exhibited a reduction of the $\left[\mathrm{Ca}^{2+}\right]$ mito $(\mathrm{F} / \mathrm{FO}=-$ $0.0486 \pm 0.0043$, Figs. $6 \mathrm{~B}$ and $6 \mathrm{C}, \mathrm{N}=4 ; \mathrm{n}=17$ ).

\section{Discussion}

Recent evidence suggests that abnormalities in cellular $\mathrm{Ca}^{2+}$ signaling are common features in the pathogenesis of a range of neurodegenerative disorders, including ALS [33]. It is well known that $\mathrm{Ca}^{2+}$ is one of the most relevant intracellular messengers essential in neuronal development, synaptic transmission and plasticity, and the regu- lation of various metabolic pathways in the brain. Further evidence for the involvement of a disruption in intracellular $\mathrm{Ca}^{2+}$ homeostasis was reported in cellular and experimental animal models; there was an absence of $\mathrm{Ca}^{2+}$ binding proteins, such as Calbindin- $\mathrm{D}_{28 \mathrm{~K}}$ and parvalbumin, in MN populations lost early in ALS [67]. Additionally, accumulation of $\mathrm{Ca}^{2+}$ into vacuoles in the mtSOD1 mice and low $\mathrm{Ca}^{2+}$ buffering in SMNs were also shown [68]. These findings agree with a quantitative comparison of $\mathrm{Ca}^{2+}$ homeostasis where a low cytosolic $\mathrm{Ca}^{2+}$ buffering capacity acts as an important risk factor for degeneration. In contrast, an increase in the cytosolic $\mathrm{Ca}^{2+}$ buffering capacity could protect vulnerable MNs from degeneration $[69,35]$. MNs store a larger amount of calcium in the mitochondria and disruption of mitochondrial $\mathrm{Ca}^{2+}$ uptake has a marked influence on both the peak amplitude of $\mathrm{Ca}^{2+}$ response as well as the clearance of $\left[\mathrm{Ca}^{2+}\right]$ i.

Our interest in studying the role of $\mathrm{Ca}^{2+}$ regulation and the impact of mitochondrial inhibition in a cellular model of ALS is based on observations that mitochondria act as local calcium buffers, thus shaping the spatiotemporal aspects of $\left[\mathrm{Ca}^{2+}\right]$ i. MN mitochondria have been shown to have a major percentage of $\mathrm{Ca}^{2+}$ sequestered intracellularly after influx through the plasma membrane $[70,71]$. Our main objective was to characterize the contribution 
A

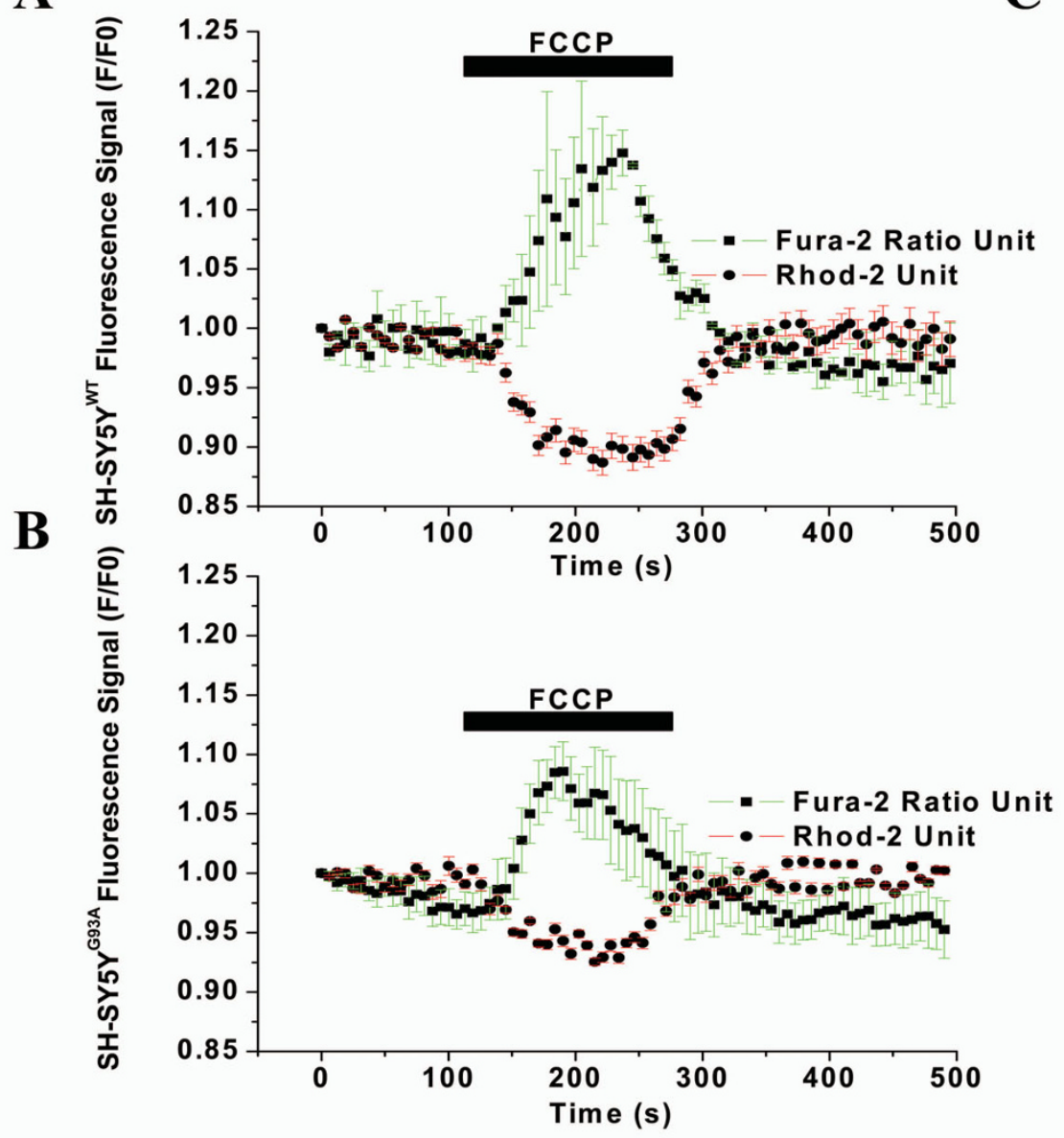

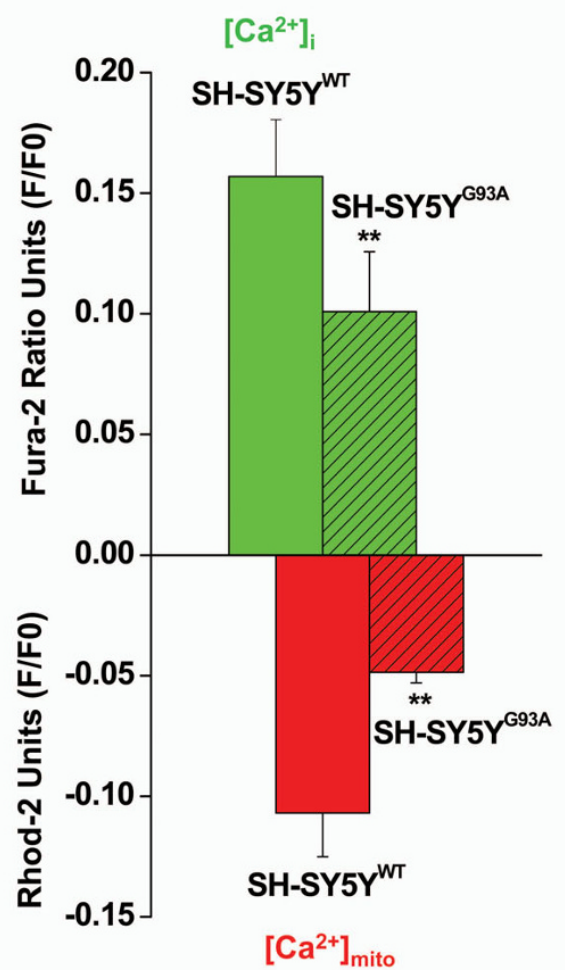

Figure 5

The simultaneous measurement of cytosolic (Fura-2) and mitochondrial (Rhod-2) calcium concentrations in WT and G93A transfected transfected SH-SY5Y cells during FCCP-evoked mitochondrial $\mathrm{Ca}^{2+}$ release. A) The kinetic profile of the FCCP-evoked $\mathrm{Ca}^{2+}$ release in the WT transfected SH-SY5Y neuroblastoma cells; the cytosolic (Error bar green, black square trace) and mitochondrial (Error bar red, black circle trace) compartment were measured simultaneously. The trace represents the mean of 5 cells in focus stimulated with $2 \mu \mathrm{M} \mathrm{FCCP} \mathrm{(5} \mathrm{point} \mathrm{smoothing).} \mathrm{B)} \mathrm{The} \mathrm{corresponding}$ kinetic profile of the FCCP-evoked $\mathrm{Ca}^{2+}$ release in the G93A transfected SH-SY5Y neuroblastoma cells; the cytosolic (Error bar green, black square trace) and mitochondrial (Error bar red, black circle trace) compartment were measured simultaneously. The trace represents the mean of 5 cells in focus stimulated with $2 \mu$ M FCCP ( 5 point smoothing). FCCP-evoked $\left[\mathrm{Ca}^{2+}\right]$ mito signals were smaller in amplitude and exhibited slower kinetics in G93A transfected SH-SY5Y cells compared to WT transfected cells and were altered from $\left[\mathrm{Ca}^{2+}\right]$ i efflux. C) A bar diagram of the cytosolic (green bar) and mitochondrial (red bar) fluorescence signals (F/F0) from WT (F/FO $=0.1569 \pm 0.0235$ for $\left[\mathrm{Ca}^{2+}\right] \mathrm{i}$ and $\mathrm{F} / \mathrm{FO}=-0.1069 \pm 0.018 \mathrm{I}$ for $\left[\mathrm{Ca}^{2+}\right] \mathrm{mito}^{2}$ hollow; $\mathrm{N}=5, \mathrm{n}=17$ ) and $\mathrm{G} 93 \mathrm{~A}\left(\mathrm{~F} / \mathrm{FO}=0.1008 \pm 0.0248\right.$ for $\left[\mathrm{Ca}^{2+}\right]$ i and $\mathrm{F} / \mathrm{FO}=-0.0486 \pm 0.0043$ for $\left[\mathrm{Ca}^{2+}\right]$ mito; striped pattern, $\mathrm{N}=4 ; \mathrm{n}=17$ ) transfected $\mathrm{SH}-\mathrm{SY} 5 Y$ neuroblastoma cells. Values represent means $\pm \mathrm{SD}$, ${ }^{* *} p<0.00 \mathrm{I}$. $\mathrm{N}=$ Number of experiments; $\mathrm{n}=$ Number of cells.

of the mitochondrial buffering of voltage-activated $\mathrm{Ca}^{2+}$ loads and how this $\mathrm{Ca}^{2+}$ regulatory mechanism is controlled. We observed that $\mathrm{Ca}^{2+}$ influx was diminished by approximately 1.86 fold in the presence of G93A compared to WT (Fig. 1). After exposure to FCCP, the capacity of G93A transfected cells to transport $\left[\mathrm{Ca}^{2+}\right]$ i to the extracellular space or to intracellular storage sites was much lower than WT transfected cells and accounted for the increased vulnerability of cells possessing mutant G93A gene.

Interestingly, the depolarization-induced $\mathrm{Ca}^{2+}$ transient in the presence of intact mitochondria was smaller in amplitude than with G93A mitochondria; excess $\mathrm{Ca}^{2+}$ emerged in the second response and was prominent in WT cells (Figs. 2A-C). This reflects the variability in $\mathrm{Ca}^{2+}$ clearing 


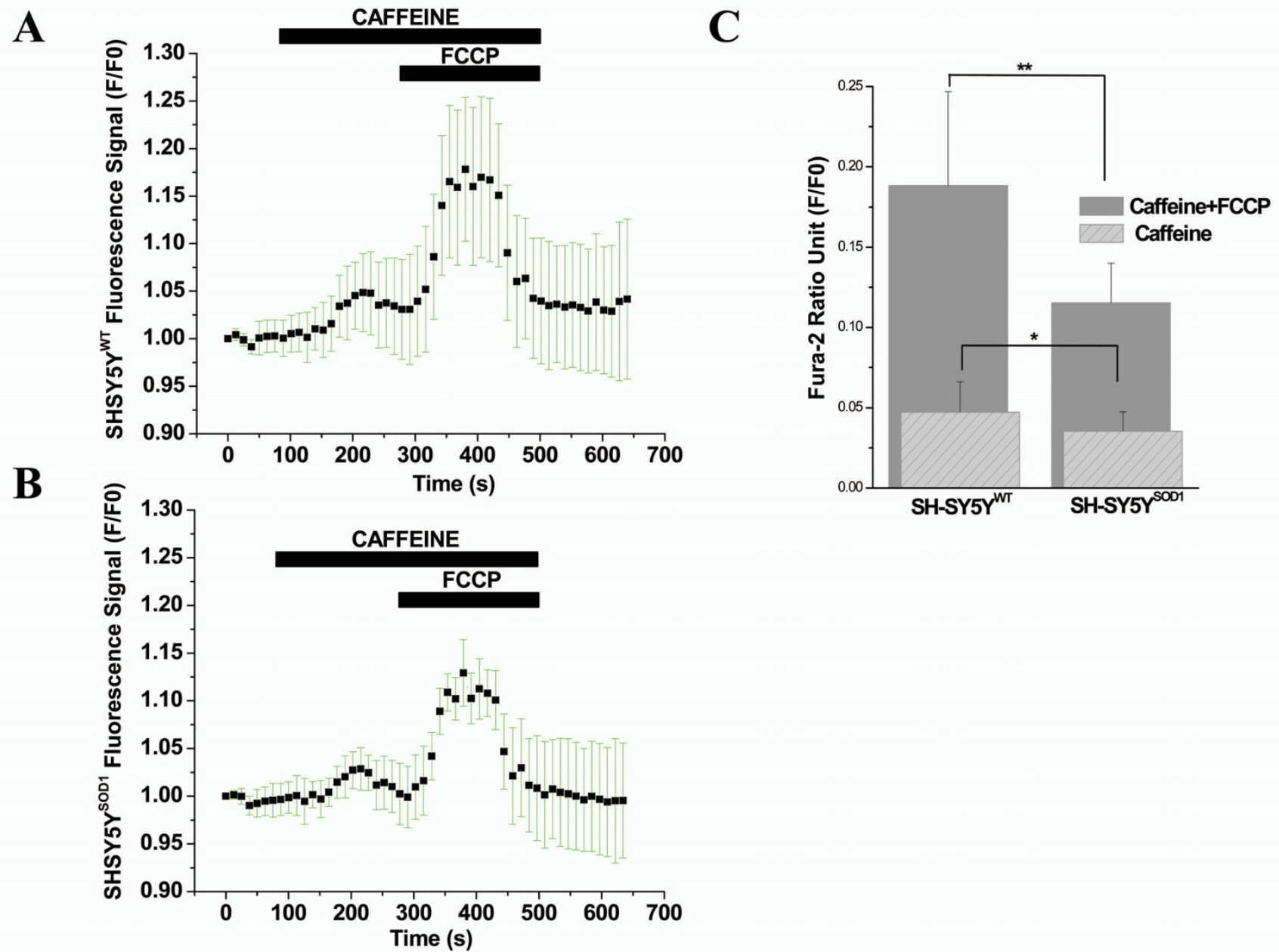

Figure 6

Caffeine stimulates $\left[\mathrm{Ca}^{2+}\right]$ i release with slower kinetics and weaker transient than the FCCP-evoked $\left[\mathrm{Ca}{ }^{2+}\right] \mathrm{i}$ signals in SH-SY5Y neuroblastoma cells, particularly in WT transfected cells compared to G93A transfected cells. A) The kinetic profile of caffeine and FCCP-evoked $\left[\mathrm{Ca}^{2+}\right]$ i release in the WT transfected SH-SY5Y neuroblastoma cells. The trace is representative of 5 cells in focus stimulated with $5 \mathrm{mM}$ caffeine and $2 \mu \mathrm{M} \mathrm{FCCP} \mathrm{(normalized} \mathrm{data,} 5$ point smoothing). B) The corresponding kinetic profile of the caffeine and FCCP-evoked [ $\mathrm{Ca}^{2+}$ ] i release in the G93A transfected SH-SY5Y cells. The trace is representative of 5 cells in focus stimulated with $5 \mathrm{mM}$ caffeine and $2 \mu \mathrm{M}$ FCCP (normalized data, 5 point smoothing). The ER and mitochondrial $\mathrm{Ca}^{2+}$ release from these two compartments were measured simultaneously. The horizontal black bars indicate the duration of stimulation by caffeine and with FCCP plus caffeine. Fura-2 AM signals are represented as F/F0. C) A bar diagram of caffeine and FCCP plus caffeine-induced $\mathrm{Ca}^{2+}$ release in the WT and G93A transfected $\mathrm{SH}-\mathrm{SY} 5 Y$ neuroblastoma cells $(\mathrm{N}=3, \mathrm{n}=14)$. Gray bars represent caffeine plus FCCP-induced $\mathrm{Ca}^{2+}$ release in $\mathrm{WT}(\mathrm{F} / \mathrm{F0}=$ $0.1883 \pm 0.0584)$ and G93A (F/FO $=0.1154 \pm 0.0246)$ transfected SH-SY5Y cells. Striped bars represent caffeine-induced Ca ${ }^{2+}$ release in WT $(F / F 0=0.047 \mathrm{I} \pm 0.0190)$ and $\mathrm{G} 93 \mathrm{~A}(\mathrm{~F} / \mathrm{FO}=0.0353 \pm 0.0120)$ transfected cells. Values represent means $\pm \mathrm{SD}$, $*_{p}<0.0$ I, $*_{p}<<0.00$ I. $\mathrm{N}=$ Number of experiments; $\mathrm{n}=$ Number of cells.

mechanisms of ALS-vulnerable and non-vulnerable MNs and agrees with data obtained from motor nerve terminals [72], cultured MNs [25], and patch-clamped hypoglossal MNs [52] in which significant mitochondrial $\mathrm{Ca}^{2+}$ uptake following voltage-activated $\mathrm{Ca}^{2+}$ influx was demonstrated. We observed that the depolarizationinduced stimulus not only interfered with the post-depolarization recovery of $\left[\mathrm{Ca}^{2+}\right] \mathrm{i}$ after FCCP challenge but also increased the peak amplitude of the FCCP-evoked
$\mathrm{Ca}^{2+}$ influx by approximately 40 and $68 \%$ in WT and G93A cells, respectively (compare Figs. $1 \mathrm{D}$ and 2C). Therefore, it is evident that in the absence of mitochondrial $\mathrm{Ca}^{2+}$ uptake, the $\left[\mathrm{Ca}^{2+}\right] \mathrm{i}$ signal is stronger, and mitochondria can actively sequester $\mathrm{Ca}^{2+}$ during an on-going $\mathrm{Ca}^{2+}$ influx as a result of the opening of voltage-gated calcium channels. A significant difference in the $\mathrm{Ca}^{2+} \mathrm{accu}-$ mulation by mitochondria in G93A and WT cells was observed and presumably due to G93A-mediated toxicity. 
Table I: Differential peak amplitudes of $\left[\mathrm{Ca}^{2+}\right]$ i release from different compartment of WT and SODI transfected SH-SY5Y cells after multidrugs intervention.

\begin{tabular}{cllllllll}
\hline & FCCP & K+FCCP & Thapsi & Thapsi+FCCP & Oligo & Oligo+FCCP & Caffeine & Caffeine+FCCP \\
\hline WT & $0.17 \pm 0.03$ & $0.24 \pm 0.06$ & $0.04 \pm 0.01$ & $0.27 \pm 0.09$ & $0.04 \pm 0.01$ & $0.22 \pm 0.07$ & $0.04 \pm 0.01$ & $0.18 \pm 0.05$ \\
SODI & $0.09 \pm 0.02^{* *}$ & $0.14 \pm 0.03^{* *}$ & $0.02 \pm 0.01 *$ & $0.12 \pm 0.02^{* *}$ & $0.02 \pm 0.01^{*}$ & $0.08 \pm 0.03^{* *}$ & $0.03 \pm 0.01^{*}$ & $0.11 \pm 0.02^{* *}$ \\
\hline
\end{tabular}

Data are expressed as mean \pm S.D.

$* p<0.01$ and $* * p<0.001$ compared with WT transfected SH-SY5Y cells.

The capacity of mitochondria to restore the $\mathrm{Ca}^{2+}$ buffering capacity of cell organelles is heavily compromised in G93A cells. The disturbance of $\mathrm{Ca}^{2+}$ trapping in intracellular storage sites and $\mathrm{Ca}^{2+}$ extrusion from the cells [41] may account for the reduced oscillations of $\left[\mathrm{Ca}^{2+}\right] \mathrm{i}$ we observed in G93A cells.

Molecular interaction underlying mitochondria-endoplasmic reticulum $\mathrm{Ca}^{2+}$ strores coupling was evaluated using thapsi and FCCP. We assume that both ER and mitochondrial intracellular pools participate in the generation of $\mathrm{Ca}^{2+}$ signals in SH-SY5Y cells shaping their spatiotemporal $\mathrm{Ca}^{2+}$ signals patterns. Thapsi- induced $\mathrm{Ca}^{2+}$ release was significantly less than that evoked by FCCP in WT and G93A transfected cells, and its kinetics were more or less similar in both genotypes (Figs. 3A-C). The application of thapsi on SH-SY5Y cells causing separate $\mathrm{Ca}^{2+}$ release response was slightly more in WT transfected cells than in G93A cells, indicating that, in the context of the G93A transfection, the ER may slightly contribute to the motor dysfunction. Furthermore, the application of FCCP after emptying ER stores with thapsi resulted in a separate release event, evident from the bigger $\left[\mathrm{Ca}^{2+}\right] \mathrm{i}$ increase. This release was higher than the general $\mathrm{Ca}^{2+}$ release caused by FCCP without emptying ER in WT transfected cells but not in G93A altered cells, which suggests an uptake of the released $\mathrm{Ca}^{2+}$ from ER by mitochondria in WT transfected cells. This further indicates the explicit action of FCCP in our working model system and the existence of two separate intracellular $\mathrm{Ca}^{2+}$ stores, in

\section{High Buffered Cell}

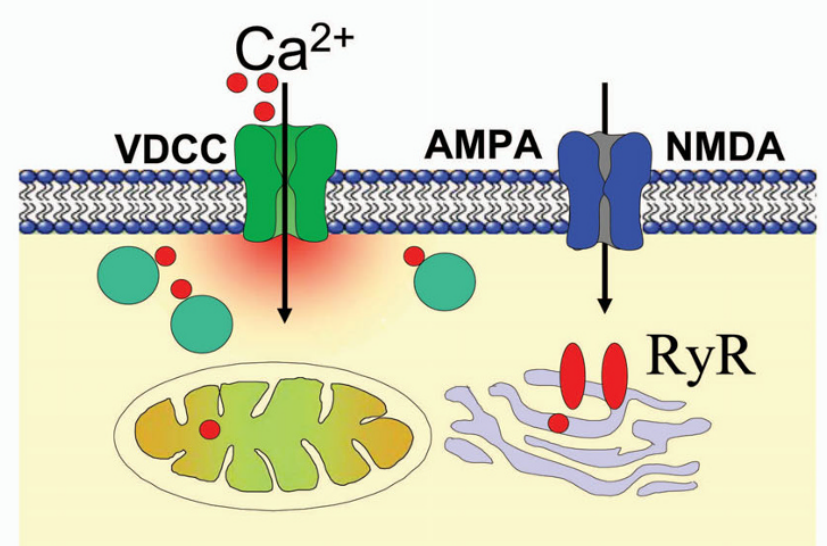

Normal Physiological condition (WT)

\section{Low Buffered Cell}

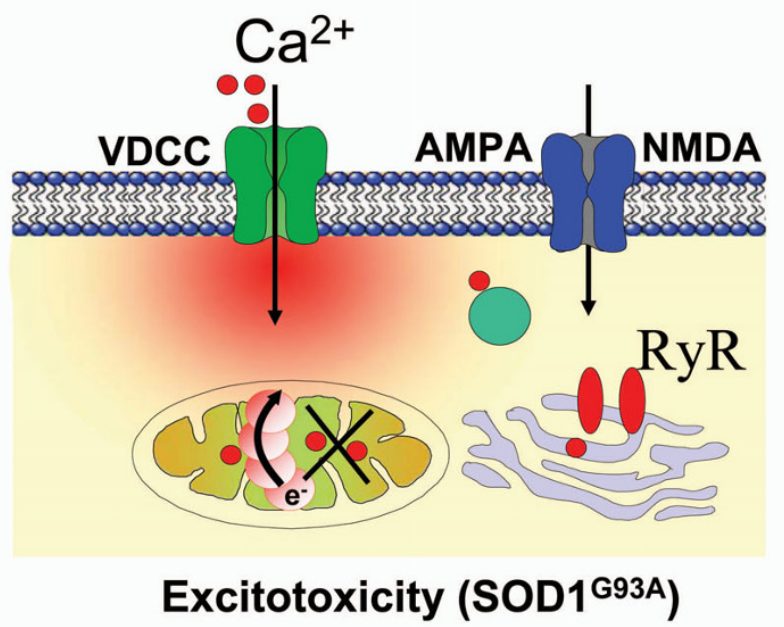

\section{Figure 7}

Low $\mathrm{Ca}^{2+}$ buffering and excitotoxicity under physiological stress and pathophysiological conditions in motor neuron (MNs). Low $\mathrm{Ca}^{2+}$ buffering in amyotrophic lateral sclerosis (ALS) vulnerable hypoglossal MNs exposes mitochondria to higher $\mathrm{Ca}^{2+}$ loads compared to highly buffered cells. Under normal physiological conditions, the neurotransmitter opens glutamate, NMDA and AMPA receptor channels, and voltage dependent $\mathrm{Ca}^{2+}$ channels (VDCC) with high glutamate release, which is taken up again by EAATI and EAAT2. This results in a small rise in intracellular calcium that can be buffered in the cell. In ALS, a disorder in the glutamate receptor channels leads to high calcium conductivity, resulting in high $\mathrm{Ca}^{2+}$ loads and increased risk for mitochondrial damage. This triggers the mitochondrial production of reactive oxygen species (ROS), which then inhibit glial EAAT2 function. This leads to further increases in the glutamate concentration at the synapse and further rises in postsynaptic calcium levels, contributing to the selective vulnerability of MNs in ALS. 
which the ER seems to play a minimal role in buffering $\left[\mathrm{Ca}^{2+}\right] \mathrm{i}$ after $\mathrm{Ca}^{2+}$ loads are imposed in G93A transfected cells, and the ER is most likely not impaired during ALSrelated motoneuron disease.

We found that ER of SH-SY5Y cells retained a very low amount of calcium (after $\mathrm{Ca}^{2+}$ release with thapsi for 6 min application) compared with mitochondria after $\mathrm{Ca}^{2+}$ elevation by FCCP ( $3 \mathrm{~min}$ ) indicating its low efficiency to sequester $\mathrm{Ca}^{2+}$ in the WT and G93A transfected SH-SY5Y cells, which was slightly higher in WT (Figs. 3A-C). This indicates that the conventional mitochondrial $\mathrm{Ca}^{2+}$ storing function dominates $\mathrm{ER} \mathrm{Ca}^{2+}$ accumulation in these cells. It is noteworthy that thapsi has a relatively very weak effect on $\mathrm{Ca}^{2+}$ release in G93A transfected cells, indicating that G93A alteration might also result in defects in ER $\mathrm{Ca}^{2+}$ handling, which may perturb functional domain and contribute to neurodegeneration. These data suggest that the ER of SH-SY5Y cells does not play a significant role in regulating $\left[\mathrm{Ca}^{2+}\right] \mathrm{i}$ at the basal level or after imposed $\mathrm{Ca}^{2+}$ loads in WT transfected cells; though minor ER contribution to the dysfunction of $\mathrm{Ca}^{2+}$ loads did not ruled out, suggesting that $\mathrm{Ca}^{2+}$ dysregulation as a result of the G93A transfection anticipates mitochondrial impairment. Our hypothesis is strengthened by the fact that previously we have shown quite similar results in an animal model of SOD1G93A mice for fALS; where cyclopiazonic acid (a specific inhibitor of $\mathrm{Ca}^{2+}$-ATPase led to a relatively slow and weak increase of $\left[\mathrm{Ca}^{2+}\right] \mathrm{i}$, which occurred with slightly higher kinetics in WT HMNs than the SOD1G93A mice HMNs [62]. This finding alongwith our results in WT and G93A transfected cells further explains that ER-dependent $\mathrm{Ca}^{2+}$ release is a minor contributor to mitochondria-mediated toxicity in G93A transfected cells as previously reported in other cell types and animal models [73,74]. Results indicate close coupling between ER and mitochondria in WT but not in G93A transfected cells which is probably impaired due to G93A transfection. The thapsireleasable $\mathrm{Ca}^{2+}$ pool in WT and G93A transfected cells (Figs 3A-C) was quite similar in quantity and temporal quality release via RyR-sensitive $\mathrm{Ca}^{2+}$ pool by caffeine (see Figs $4 \mathrm{~A}-\mathrm{C}$ ). This observations suggests that $\mathrm{Ca}^{2+}$ uptake by RyR-responsive pool is also sensitive to thapsi. These findings also indicate that thapsi increases $\left[\mathrm{Ca}^{2+}\right] \mathrm{i}$ by inhibiting $\mathrm{Ca}^{2+}$ uptake into multiple intracellular $\mathrm{Ca}^{2+}$ pools and by also promoting entry of extracellular $\mathrm{Ca}^{2+}$ dominantly in WT but not in G93A transfected cells. The exact molecular interactions defining the organization of mitochondria, ER and other $\mathrm{Ca}^{2+}$ sources varies among different cell types, are questions that remain unanswered but are interesting areas for future investigations.

We expect a decrease in cellular ATP levels during inhibition of mitochondrial electron transport by FCCP and this may affect release of $\left[\mathrm{Ca}^{2+}\right]$ i. To test the impact of ATP depletion on regulation of $\left[\mathrm{Ca}^{2+}\right] \mathrm{i}$, oligo $(5 \mu \mathrm{g} / \mathrm{ml})$ was added before FCCP application. Oligo does not influence $\left[\mathrm{Ca}^{2+}\right]$ i heavily and left basal $\mathrm{Ca}^{2+}$ levels, as well as recovery times of $\mathrm{Ca}^{2+}$ transients, unaffected for upto several minutes ( 6 min application; Figs $5 \mathrm{~A}-\mathrm{C}$ ) and therefore amplitude of evoke [ $\left.\mathrm{Ca}^{2+}\right]$ i transients was clearly attributable to FCCP. Since application of oligo alone did not affect the $\left[\mathrm{Ca}^{2+}\right] \mathrm{i}$ transients therefore the effect of FCCP is clearly attributable to collapse of mitochondria, and not to inhibition of ATP-synthesis. We assume that the time course of ATP depletion by FCCP is slower but the increase of cytosolic calcium by FCCP is immediate and therefore there is no causal relationships have been demonstrated between fall in ATP level and increase of $\left[\mathrm{Ca}^{2+}\right] \mathrm{i}$. These results are in agreement with those from studies of SOD1G93A mice in sensitivity of HMNs mitochondria to oligo [62].

Using the CCD camera imaging system, we clearly separated the dynamic profiles of $\left[\mathrm{Ca}^{2+}\right] \mathrm{i}$ and $\left[\mathrm{Ca}^{2+}\right]$ mito. Using this method, we demonstrated that in WT cells, the FCCP-evoked increase in $\left[\mathrm{Ca}^{2+}\right] \mathrm{i}$ was mainly due to $\left[\mathrm{Ca}^{2+}\right] \mathrm{i}$ alone. However, in G93A cells, the FCCP-evoked $\left[\mathrm{Ca}^{2+}\right] \mathrm{i}$ was less, exhibited slower kinetics, and reduced $\left[\mathrm{Ca}^{2+}\right]$ mito. This suggests that cells with G93A have a lower affinity for mitochondrial $\mathrm{Ca}^{2+}$ upload and likely represents severely disturbed and vulnerable mitochondria. In this study, for the first time, the simultaneous determination of $\left[\mathrm{Ca}^{2+}\right] \mathrm{i}$ and $\left[\mathrm{Ca}^{2+}\right]$ mito in WT and G93A transfected SH-SY5Y cells, a culture model of motor neuron disease was achieved (Figs 6A-C). This data is in agreement with previous findings that G93A cells exhibit damaged and stressed mitochondria [6] and increased ROS [47].

Different intracellular pools participate in the generation of neuronal $\mathrm{Ca}^{2+}$ signals, shaping their spatio-temporal patterns, and the cell life-death cycle. Mitochondria, in the kinetic and hot spot hypothesis, and the ER, by different classes of channels with distinct properties and highly defined expression patterns, have been implicated in the regulation of $\left[\mathrm{Ca}^{2+}\right]_{i}$ in many systems $[41,42]$. Caffeine was used to investigate ER-dependent $\mathrm{Ca}^{2+}$ release and we found that it evoked a small and slow increase in $\left[\mathrm{Ca}^{2+}\right] \mathrm{i}$ with slightly faster kinetics in WT cells than G93A cells. This further suggests that ER-dependent $\mathrm{Ca}^{2+}$ release has a minor contribution in the mitochondria-mediated toxicity of G93A. The rate of increase in Fura-2 fluorescence following caffeine application was slower and did not resume the baseline, which is likely due to the slow activity of the mitochondrial $\mathrm{Na}^{+} / \mathrm{Ca}^{2+}$ exchanger, the major pathway for mitochondrial $\mathrm{Ca}^{2+}$ efflux [75]. Observations of different pharmacological conditions support the concept that the presence of G93A severely disrupts mitochondrial $\mathrm{Ca}^{2+}$ regulation. It is also interesting to note that 
the rate of increase in Fura-2 fluorescence signals following caffeine application was slightly slower compared to FCCP-evoked signals and did not achieve the baseline within a few minutes. This suggests that the dye accumulates in the mitochondria and the mitochondrial uptake and release event is prominently operated by $\mathrm{Ca}^{2+}$ efflux rather than by the store-operated $\mathrm{Ca}^{2+}$ uptake and release phenomenon. Our fluorescence system may be a valuable tool to determine mitochondrial and $\mathrm{Ca}^{2+}$-related defects during G93A-mediated MN degeneration, which closely parallels the incidence of neuronal death in G93A transfected SH-SY5Y cells. Quantitative values of normalized Fura-2 fluorescence signals after different drugs interventions are compared in Table 1.

Despite rigorous research since Charcot's description more than 130 years ago, the molecular abnormalities leading to the damage of specific MNs in ALS are still unknown. The selective vulnerability of MNs in ALSrelated disease and associated cell culture models is closely linked to exceptional $\mathrm{Ca}^{2+}$ signaling mechanisms that are part of the physiological cell function, but seemingly also enhances the risk of $\mathrm{Ca}^{2+}$ homeostasis disruption and mitochondrial dysfunction in vulnerable cells. Earlier studies suggested that uncontrolled $\mathrm{Ca}^{2+}$ entry and inefficient calcium sequestering cause selective damage leading to the formation of vacuoles derived from the degenerating mitochondria in the MNs of the mouse model of ALS $[12,76,77]$. In contrast to most other neurons, MNs have a low $\mathrm{Ca}^{2+}$-buffering capacity due to the low expression of $\mathrm{Ca}^{2+}$-buffering proteins and a high number of $\mathrm{Ca}^{2+}$-permeable AMPA receptors resulting from low expression of the GluR2 subunit. The combination of these two properties seems to be intrinsic to MNs and is most likely essential for their normal function. However, under pathological conditions, MNs may become over-stimulated by glutamate and overwhelmed by $\mathrm{Ca}^{2+}$; though, whether downstream pathways activated by the intracellular $\mathrm{Ca}^{2+}$ increase are different in $\mathrm{MNs}$ compared to other neurons is not yet known.

\section{Conclusion}

Our experiments identified specialized $\mathrm{Ca}^{2+}$ homeostasis characterized by low cytosolic $\mathrm{Ca}^{2+}$ buffering in which mitochondria play a major role in the regulation of $\left[\mathrm{Ca}^{2+}\right]_{i}$ transients in vulnerable MNs. Low cytosolic $\mathrm{Ca}^{2+}$ buffering enhances the role of low affinity organelle buffers, such as mitochondria, in the cell. For example, large and long-lasting $\mathrm{Ca}^{2+}$ domains around influx sites enhance the risk of toxic $\mathrm{Ca}^{2+}$ accumulations and subsequent activation of $\mathrm{Ca}^{2+}$-dependent neurodegenerative pathways under excitotoxic conditions. Indeed, a strong contribution of mitochondria, as opposed to ER, $\mathrm{Ca}^{2+}$ uptake to the buffering of $\mathrm{Ca}^{2+}$ profiles was recently demonstrated $[19,52,62]$. There are two reasons that the prominent role of mitochondria in the regulation of moderate $\mathrm{Ca}^{2+}$ loads in MNs has important implications for pathological conditions such as ALS. First, the amount of $\mathrm{Ca}^{2+}$ taken up by the mitochondria is probably higher in MNs than other cell types [25,78]. These high $\mathrm{Ca}^{2+}$ loads enhance the risk for ROS generation, which may play a major role in initiating the death cycle resulting in $\mathrm{MN}$ degeneration [29]. Second, our experiments provide evidence that cytosolic $\mathrm{Ca}^{2+}$ depends on intact mitochondrial $\mathrm{Ca}^{2+}$ uptake. Thus, when mitochondrial $\mathrm{Ca}^{2+}$ uptake is disturbed, as was seen in G93A cells, MNs are directly put at risk of accumulating basal $\mathrm{Ca}^{2+}$ levels during repetitive oscillations. Additionally, the decreased ability to limit $\mathrm{Ca}^{2+}$ transient amplitudes in the cytosol and, in particular, local domains when mitochondria are depolarized enhances the risk of initiating $\mathrm{Ca}^{2+}$ dependent neurodegenerative pathways leading to cell death. A summary of the identified mechanisms is given in Fig. 7; in vulnerable MNs, the calcium buffering machinery is represented by the predominance of mitochondria and calcium binding proteins.

\section{Abbreviations}

ALS: amyotrophic lateral sclerosis; AM: acetoxy methyl ester; CCD: charge cooled device; DMEM: Dulbecco's modified Eagle medium; DMSO: dimethyl sulfoxide; ER: endoplasmic reticulum; F: fluorescence; fALS: familial amyotrophic lateral sclerosis; FCCP: Carbonyl cyanide p(trifluoromethoxy) phenylhydrazone; FCS: fetal calf serum; FMNs: facial motoneurons; HMNs: hypoglossal motoneurons; hALS: human amyotrophic lateral sclerosis; MCU: mitochondrial calcium uniporter; $\mathrm{MN}$ : motoneuron; mtSOD1: mutant $\mathrm{Cu} / \mathrm{Zn}$ superoxide dismutase1; oligo: oligomycin; ROI: regions of interest; ROS: reactive oxygen species; RPMI 1640: Roswell Park Memorial Institute medium; RyR: ryanodine receptor; SD: standard deviation; SOD1: $\mathrm{Cu} / \mathrm{Zn}$ superoxide dismutase1; $\mathrm{TPP}^{+}$: Tetraphenylphosphonium salt; thapsi: thapsigargin; $\left[\mathrm{Ca}^{2+}\right]$ i: cytosolic calcium; $\left[\mathrm{Ca}^{2+}\right]$ mito: mitochondrial calcium; WT: wild type; $\Delta \psi_{\mathrm{m}}$ : mitochondrial membrane potential.

\section{Competing interests}

The authors declare that they have no competing interests.

\section{Authors' contributions}

MKJ performed the experiments, analyzed the data, and wrote the initial version of the manuscript. WDZ, MG and RN established the primary cultured human SH-SH5Y cell line and maintained them during the course of the project. Cell lines expressing either wild-type (Wt) human SOD1 or the G93A mutants of this enzyme were produced by AF and MTC. CL, AZ, MTC and RN participated in the design of the study and participated in the organization of financial support. BUK is the principal investigator of the project. Besides providing laboratory support and supervi- 
sion, he is primarily responsible for financial support and project management. All authors read and approved the final manuscript.

\section{Additional material}

\section{Additional file 1}

Schematic representation of method and spectra. Schematic representation of the (A) CCD-imaging setup used for calcium imaging and (B) simultaneous measurements of $\left[\mathrm{Ca}^{2+}\right]$ i and $\left[\mathrm{Ca}^{2+}\right]$ mito in SH-SY5Y cell line preparations. C) Spectral view of calcium imaging. The fluorescence excitation at $510 \mathrm{~nm}$ and emission detected at $340 \mathrm{~nm}$ are shown for $\mathrm{Ca}^{2+}$-saturated (A) and $\mathrm{Ca}^{2+-}$ free (B) Fura-2 in pH 7.2 buffer. D) Spectral view of simultaneous $\left[\mathrm{Ca}^{2+}\right] \mathrm{i}$ and $\left[\mathrm{Ca}^{2+}\right]$ mito measurements generated by the Molecular Probes spectral view program. Fluorescence excitation of fura-2 was done at $390 \mathrm{~nm}$ and $550 \mathrm{~nm}$ of rhod-2, respectively; emission was at $510 \mathrm{~nm}$ (fura-2, solid line) and at $600 \mathrm{~nm}$ (rhod2) separated by a $565 \mathrm{~nm}$ dichroic mirror.

Click here for file

[http://www.biomedcentral.com/content/supplementary/14712202-10-64-S1.tiff]

\section{Additional file 2}

Mitochondria-dependent responses of cytosolic calcium in SH-SY5Y neuroblastoma cells (non-transfected parental cell line) loaded with Fura-2 AM and superfused with DMEM medium. A) Representative CCD camera photomicrograph of Fura-2 AM loaded SH-SY5Y cells. Scale bar is $10 \mu \mathrm{m}$. B) FCCP-evoked mitochondria-dependent responses of cytosolic calcium.

Click here for file

[http://www.biomedcentral.com/content/supplementary/14712202-10-64-S2.tiff]

\section{Acknowledgements}

We would like to thank Drs Saju Balakrishnan, Friederike von Lewinski, Michael Müller, Eike Schomburg and Diethelm Richter for their valuable discussions. This research was supported by grants from the Bernstein Center for Computational Neuroscience (BCCN), Göttingen, BMBF project Bioprofile 03I3610 A, the consortium EU - Eranet ERMCC and Else KrönerFresenius-Stiftung.

\section{References}

I. Bruijn LI, Houseweart MK, Kato S, Anderson KL, Anderson SD, Ohama E, Reaume AG, Scott RW, Cleveland DW: Aggregation and motorneuron toxicity of an ALS-linked SODI mutant independent from wildtype SODI. Science 1998, 28I:185I-I854.

2. Rowland LP, Shneider NA: Amyotrophic Lateral Sclerosis. N Engl J Med 200I, 344:1688-1700.

3. Rosen DR, Siddique T, Patterson D, Figlewicz DA, Sapp P, Hentati A, Donaldson D, Goto J, O'Regan JP, Deng HX, et al.: Mutations in Cu/ Zn superoxide dismutase gene are associated with familial amyotrophic lateral sclerosis. Nature 1993, 362:59-62.

4. Rosen DR, Bowling AC, Patterson D, Usdin TB, Sapp P, Mezey E, McKenna-Yasek D, O'Regan J, Rahmani Z, Ferrante RJ, et al.: A frequent ala 4 to val superoxide dismutase-I mutation is associated with a rapidly progressive familial amyotrophic lateral sclerosis. Hum Mol Genet 1994, 3:98I-7.

5. Gurney ME, Pu H, Chiu AY, Dal Canto MC, Polchow CY, Alexander DD, Caliendo J, Hentati A, Kwon YW, Deng H-X, Chen W, Zhai P, Sufit RL, Siddique T: Motor neuron degeneration in mice that express a human $\mathrm{Cu}, \mathrm{Zn}$ superoxide dismutase. Science 1994 , 264: $1772-1775$.
6. Carri MT, Ferri A, Battistoni A, Famhy L, Gabbianelli R, Poccia F, Rotilio G: Expression of a $\mathrm{Cu}, \mathrm{Zn}$ superoxide dismutase typical of familial amyotrophic lateral sclerosis induces mitochondrial alteration and increase of cytosolic $\mathrm{Ca}^{2+}$ concentration in transfected neuroblastoma SH-SY5Y cells. FEBS Lett 1997, 4|4:365-8.

7. Andersen PM, Sims KB, Xin WW, Kiely R, O'Neill G, Ravits J, Pioro E, Harati Y, Brower RD, Levine JS, Heinicke HU, Seltzer W, Boss M, Brown RH Jr: Sixteen novel mutations in the $\mathrm{Cu} / \mathrm{Zn}$ superoxide dismutase gene in amyotrophic lateral sclerosis: a decade of discoveries defects and disputes. Amyotroph Lateral. Scler Other Motor Neuron Disord 2003, 4:62-73.

8. Bowling AC, Schulz JB, Brown RH Jr, Beal MF: Superoxide dismutase activity, oxidative damage, and mitochondrial energy metabolism in familial and sporadic amyotrophic lateral sclerosis. J Neurochem 1993, 61:2322-5.

9. Wong PC, Pardo CA, Borchelt DR, Lee MK, Copeland NG, Jenkins NA, Sisodia SS, Cleveland DW, Price DL: An adverse property of a familial ALS-linked SODI mutation causes motor neuron disease characterized by vacuolar degeneration of mitochondria. Neuron 1995, 14:1105-16.

10. Sasaki S, Iwata M: Ultrastructural study of synapses in the anterior horn neurons of patients with amyotrophic lateral sclerosis. Neurosci Lett 1996, 204:53-6.

II. Sasaki S, Iwata M: Impairment of fast axonal transport in the proximal axons of anterior horn neurons in amyotrophic lateral sclerosis. Neurology 1996, 47:535-540.

12. Kong J, Xu Z: Massive mitochondrial degeneration in motor neurons triggers the onset of amyotrophic lateral sclerosis in mice expressing a mutant SODI. J Neurosci 1998, 18:324I-50.

13. Jaarsma D, Rognoni F, Duijn WV, Verspaget HW, Haasdijk ED, Holstege JC: $\mathrm{Cu}-\mathbf{Z n}$ superoxide dismutase (SODI) accumulates in vacuolated mitochondria in transgenic mice expressing amyotrophic lateral sclerosis-linked SODI mutations. Acta Neuropath 200I, 102:293-305.

14. Menzies FM, Cookson MR, Taylor RW, Turnbull DM, ChrzanowskaLightowlers ZM, Dong L, Figlewicz DA, Shaw PJ: Mitochondrial dysfunction in a cell culture model of familial amyotrophic lateral sclerosis. Brain 2002, I25:1522-I533.

15. Menzies FM, Ince PG, Shaw PJ: Mitochondrial involvement in amyotrophic lateral sclerosis. Neurochem Inter 2002, 40:543-551.

16. Wiedemann FR, Winkler K, Kuznetsov AV, Bartels C, Vielhaber S, Feistner H, Kunz WS: Impairment of mitochondrial function in skeletal muscle of patients with amyotrophic lateral sclerosis. J Neurol Sci 1998, I56:65-72

17. Wiedemann FR, Manfredi G, Mawrin C, Beal MF, Schon EA: Mitochondrial DNA and respiratory chain function in spinal cords of ALS patients. J Neurochem 2002, 80:616-625.

18. Vielhaber S, Kunz D, Winkler K, Wiedemann FR, Kirches E, Feistner $H$, Heinze HJ, Elger CE, Schubert W, Kunz WS: Mitochondrial DNA abnormalities in skeletal muscle of patients with sporadic amyotrophic lateral sclerosis. Brain 2000, I 23(Pt 7): $1339-48$

19. Bergmann F, Keller BU: Impact of mitochondrial inhibition on excitability and cytosolic $\mathrm{Ca}^{2+}$ levels in brainstem motoneurons from mouse. J Physiol 2004, 555:45-59.

20. Ferri A, Gabbianelli R, Casciati A, Paolucci E, Rotilio G, Carrì MT: Calcineurin activity is regulated both by redox compounds and by mutant familial amyotrophic lateral sclerosis-superoxide dismutase. J Neurochem 2000, 75:606-13.

21. Rao SD, Weiss JH: Excitotoxic and oxidative cross-talk between motor neurons and glia in ALS pathogenesis. Trends Neurosci 2004, 27: 17-23.

22. Rothstein JD, Martin LJ, Kuncl RW: Decreased glutamate transport by the brain and spinal cord in amyotrophic lateral sclerosis. N Engl J Med 1992, 326: | 464-8.

23. Rothstein JD, Van Kammen M, Levey AI, Martin LJ, Kuncl RW: Selective loss of glial glutamate transporter GLT-I in amyotrophic lateral sclerosis. Ann Neurol 1995, 38:73-84.

24. Trotti D, Rolfs A, Danbolt NC, Brown RH, Hediger MA: SODI mutants linked to amyotrophic lateral sclerosis selectively inactivate a glial glutamate transporter. Nat Neurosci 1999, 2:427-433. 
25. Carriedo SG, Sensi SL, Yin HZ, Weiss JH: AMPA exposures induce mitochondrial $\mathrm{Ca}^{2+}$ overload and $\mathrm{ROS}$ generation in spinal motor neurons in vitro. J Neurosci 2000, 20:240-50.

26. Maragakis NJ, Rothstein JD: Glutamate transporters in neurologic disease. Arch Neurol 200I, 58:365-70.

27. Heath PR, Shaw PJ: Update on the glutamatergic neurotransmitter system and the role of excitotoxicity in amyotrophic lateral sclerosis. Muscle Nerve 2002, 26:438-58.

28. Guo H, Lai L, Butchbach ME, Stockinger MP, Shan X, Bishop GA, Lin $C L$ : Increased expression of the glial glutamate transporter EAAT2 modulates excitotoxicity and delays the onset but not the outcome of ALS in mice. Hum Mol Genet 2003 , I 2:2519-32.

29. Rao SD, Yin HZ, Weiss JH: Disruption of glial glutamate transport by reactive oxygen species produced in motor neurons. J Neurosci 2003, 23:2627-2633.

30. Llinas R, Sugimori M, Cherksey BD, Smith RG, Delbono O, Stefani E Appel SH: IgG from amyotrophic lateral sclerosis patients increases current through P-type calcium channels in mammalian cerebellar Purkinje cells and in isolated channel protein in lipid bilayer. Proc Natl Acad Sci USA 1993, 90: I I 743-7.

31. Appel SH, Smith RG, Engelhardt JI, Stefani E: Evidence for autoimmunity in amyotrophic lateral sclerosis. I Neurol Sci 1994 I 24(Suppl): I4-9.

32. Appel SH, Smith RG, Alexianu M, Siklos L, Engelhardt J, Colom LV, Stefani E: Increased intracellular calcium triggered by immune mechanisms in amyotrophic lateral sclerosis. Clin Neurosci 1996, 3(6):368-374.

33. Mattson MP, LaFerla FM, Chan SL, Leissring MA, Shepel PN, Geiger JD: Calcium signaling in the ER: its role in neuronal plasticity and neurodegenerative disorders. Trends Neurosci 2000 23:222-229.

34. Beal MF: Oxidatively modified proteins in aging and disease. Free Radical Biology and Medicine 2002, 32:797-803.

35. Bosch L Van Den, Schwaller B, Vleminckx V, Meijers B, Stork S, Ruehlicke T, Van Houtte E, Klaassen H, Celio MR, Missiaen L: Protective effect of parvalbumin on excitotoxic motor neuron death. Exp Neurol 2002, I 74: I50-I6I.

36. Simpson EP, Yen AA, Appel SH: Oxidative Stress: a common denominator in the pathogenesis of amyotrophic lateral sclerosis. Curr Opin Rheumatol 2003, I 5:730-736.

37. Tateno M, Sadakata H, Tanaka M, Itohara S, Shin RM, Miura M, Mas uda M, Aosaki T, Urushitani M, Misawa H, Takahashi R: Calciumpermeable AMPA receptors promote misfolding of mutant SODI protein and development of amyotrophic lateral sclerosis in a transgenic mouse model. Hum Mol Genet 2004 13:2183-2196.

38. Von Lewinski $\mathrm{F}$, Keller $\mathrm{BU}: \mathrm{Ca}^{2+}$, mitochondria and selective motoneuron vulnerability: implications for ALS. Trends Neurosci 2005, 28:494-500.

39. Goodall EF, Morrison KE: Amyotrophic lateral sclerosis (motor neuron disease): proposed mechanisms and pathways to treatment. Expert Rev Mol Med 2006, 8:I-22.

40. Goos M, Zech WD, Jaiswal MK, Balakrishnan S, Ebert S, Mitchell T, Carrì MT, Keller BU, Nau R: Expression of a $\mathbf{C u}, \mathbf{Z n}$ superoxide dismutase typical for familial amyotrophic lateral sclerosis increases the vulnerability of neuroblastoma cells to infectious injury. BMC Infect Dis 2007, I 2(7): I31.

4I. Herrington J, Park YB, Babcock DF, Hille B: Dominant role of mitochondria in clearance of large $\mathrm{Ca}^{2+}$ loads from rat adrenal chromaffin cells. Neuron 1996, 16:219-228.

42. Schinder AF, Olson EC, Spitzer NC, Montal M: Mitochondrial dysfunction is a primary event in glutamate neurotoxicity. J Neurosci 1996, 16:6125-33.

43. Bar PR: Motor neuron disease in vitro: the use of cultured motor neurons to study amyotrophic lateral sclerosis. Eur Pharmacol 2000, 405:285-295.

44. Sachiko T, Seiji K, Kazuyoshi S, Jun T, Riichiro K, Ichiro Y, Shoichi Y, Masayoshi T, Hidenao S: Proteasome inhibition induces selective motor neuron death in organotypic slice cultures. I Neurosci Res 2005, 82:443-45I.

45. Avossa D, Grandolfo M, Mazzarol F, Zatta M, Ballerini L: Early signs of motoneuron vulnerability in a disease model system: Characterization of transverse slice cultures of spinal cord isolated from embryonic ALS mice. Neuroscience 2006, |38:1179-1194.
46. Carri MT, Ferri A, Cozzolino M, Calabrese L, Rotilio G: Neurodegeneration in amyotrophic lateral sclerosis: the role of oxidative stress and altered homeostasis of metals. Brain Res Bull 2003, $61: 365-374$.

47. Ciriolo MR, De Martino A, Lafavia E, Rossi L, Carrì MT, Rotilio G: Cu, Zn superoxide dismutase-dependent apoptosis induced by nitric oxide in neuronal cells. J Biol Chem 2000, 275:5065-5072.

48. Gabbianelli R, Ferri A, Rotilio G, Carrì MT: Aberrant copper chemistry as a major mediator of oxidative stress in a human cellular model of amyotrophic lateral sclerosis. J Neurochem 1999, 73: $1175-80$

49. Ferri A, Nencini M, Casciati A, Cozzolino M, Angelini DF, Longone $P$, Spalloni A, Rotilio G, Carrì MT: Cell death in amyotrophic lateral sclerosis: interplay between neuronal and glial cells. FASEB 2004, I 8: $126 \mid-3$

50. Di Poto C, ladarola P, Bardoni AM, Passadore I, Giorgetti S, Cereda C, Carrì MT, Ceroni M, Salvini R: 2-DE and MALDI-TOF-MS for a comparative analysis of proteins expressed in different cellular models of amyotrophic lateral sclerosis. Electrophoresis 2007, 28:4320-9.

5I. Ladewig T, Keller BU: Simultaneous patch-clamp recording and calcium imaging in a rhythmically active neuronal network in the brainstem slice preparation from mouse. Pflugers Arch 2000, 440:322-332

52. Ladewig T, Kloppenburg P, Lalley PM, Zipfel WR, Webb WW, Keller BU: Spatial profiles of store-dependent calcium release in motoneurones of the nucleus hypoglossus from newborn mouse. J Physiol 2003, 547:775-787.

53. Duchen MR: Mitochondria and $\mathbf{C a}^{2+}$ in cell physiology and pathophysiology. Cell Calcium 2000, 28:339-348.

54. Duchen MR: Mitochondria and calcium: from cell signalling to cell death. I Physiol 2000, I 5:57-68.

55. Nicholls DG, Budd SL: Mitochondria and neuronal survival. Physiol Rev 2000, 80:315-360.

56. Billups B, Forsythe ID: Presynaptic mitochondrial calcium sequestration influences transmission at mammalian central synapses. I Neurosci 2002, 22:5840-5847.

57. Sagara $Y$, Inesi G: Inhibition of the sarcoplasmic reticulum $\mathbf{C a}^{2+}$ transport ATPase by thapsigargin at subnanomolar concentrations. I Biol Chem 1991, 266:13503-6.

58. Svichar N, Shmigol A, Verkhratsky A, Kostyuk P: ATP induces $\mathrm{Ca2}+$ release from IP3-sensitive $\mathbf{C a 2 +}$ stores exclusively in large DRG neurones. Neuroreport 1997, 8: I555-I559.

59. Solovyova N, Veselovsky N, Toescu EC, Verkhratsky A: Ca (2+) dynamics in the lumen of the endoplasmic reticulum in sensory neurons: direct visualization of $\mathrm{Ca}(2+)$-induced $\mathrm{Ca}(2+)$ release triggered by physiological Ca (2+) entry. EMBO J 2002, 2I:622-30.

60. Kirichok Y, Krapivinsky G, Clapham DE: The mitochondrial calcium uniporter is a highly selective ion channel. Nature 2004 22:360-4

61. Lytton J, Westlin M, Hanley MR: Thapsigargin inhibits the sarcoplasmic or endoplasmic reticulum Ca-ATPase family of calcium pumps. J Biol Chem I99I, 266:I7067-7I.

62. Jaiswal MK, Keller BU: Cu/Zn superoxide dismutase typical for familial amyotrophic lateral sclerosis increases the vulnerability of mitochondria and perturbs $\mathrm{Ca}^{2+}$ homeostasis in SOD I G93A mice. Mol Pharmacol 2009, 75:478-489.

63. Wei H, Perry DC: Dantrolene is cytoprotective in two models of neuronal cell death. J Neurochem 1996, 67:2390-2398.

64. Friel DD, Tsien RW: An FCCP-sensitive $\mathbf{C a}^{2+}$ store in bullfrog sympathetic neurons and its participation in stimulusevoked changes in [Ca $\left.{ }^{2+}\right]$ i. J Neurosci 1994, I 4:4007-4024.

65. Budd SL, Nicholls DG: A reevaluation of the role of mitochondria in neuronal $\mathbf{C a}^{2+}$ homeostasis. I Neurochem 1996, 66:403-4II

66. David G, Barrett JN, Barrett EF: Evidence that mitochondria buffer physiological $\mathrm{Ca}^{2+}$ loads in lizard motor nerve terminals. J Physiol 1998, 509:59-65.

67. Alexianu ME, Ho BK, Mohamed AH, La Bella V, Smith RG, Appel SH: The role of calcium-binding proteins in selective motoneuron vulnerability in amyotrophic lateral sclerosis. Ann Neuro 1994, 36:846-858.

68. Siklós L, Engelhardt JI, Alexianu ME, Gurney ME, Siddique T, Appel SH: Intracellular calcium parallels motoneuron degeneration in SOD-I mutant mice. J Neuropathol Exp Neurol 1998, 57:57|-87. 
69. Beers DR, Ho BK, Siklos L, Alexianu ME, Mosier DR, Habib Mohamed A, Otsuka Y, Kozovska ME, Smith RE, McAlhany RG, Appel SH: Parvalbumin overexpression alters immune-mediated increases in intracellular calcium, and delays disease onset in a transgenic model of familial amyotrophic lateral sclerosis. J Neurochem 200I, 79:499-509.

70. Balakrishnan S, Bergmann F, Keller BU: Mitochondria differentially regulate $[\mathrm{Ca}] \mathrm{i}$ in brainstem motoneurons from mouse: implications for selective motoneuron vulnerability [abstract]. Program No. 340.16, Abstract Viewer and Itinerary Planner, Society for Neuroscience 2004 [http://www.sfn.org/ index.aspx? pagename $=$ abstracts ampublications].

71. Jaiswal MK, Stefan H, Balakrishnan S, Schomburg ED, Keller BU: Disruptions of $[\mathrm{Ca}] \mathrm{i}$ and mitochondria in the adult SOD IG93A mouse model of ALS: evidence from recordings in vitro and in vivo. Program No. 508.8, 2006, In 2006 Abstract Viewer and ltinerary Planner, Society for Neuroscience [http://www.sfn.org/ index.aspx? pagename $=$ abstracts ampublications].

72. David G, Barrett EF: Stimulation-evoked increases in cytosolic $\left[\mathrm{Ca}^{2+}\right]$ in mouse motor nerve terminals are limited by mitochondrial uptake and are temperature-dependent. J Neurosci 2000, 20:7290-7296.

73. Fill M, Copello JA: Ryanodine receptor calcium release channels. Physiol Rev 2002, 82:893-922.

74. Sher AA, Hinch R, Noble PJ, Gavaghan DJ, Noble D: Functional significance of $\mathrm{Na}^{+} / \mathrm{Ca}^{2+}$ exchangers co-localization with ryanodine receptors. Ann N Y Acad Sci 2007, 1099:21 5-220.

75. Leoty C, Huchet-Cadiou C, Talon S, Choisy S, Hleihel W: Caffeine stimulates the reverse mode of $\mathrm{Na}^{+} / \mathrm{Ca}^{2+}$ exchanger in ferret ventricular muscled. Acta Physiologica Scandinavica 200I, 172:27-37.

76. Sasaki S, Warita H, Murakami T, Abe K, Iwata M: Ultrastructural study of mitochondria in the spinal cord of transgenic mice with a G93A mutant SODI gene. Acta Neuropathol 2004, 107:46I-74.

77. Sasaki S, Warita H, Abe K, Iwata M: Impairment of axonal transport in the axon hillock and the initial segment of anterior horn neurons in transgenic mice with a G93A mutant SOD I gene. Acta Neuropathol 2005, I 1 0:48-56.

78. Sen I, Nalini A, Joshi NB, Joshi PG: Cerebrospinal fluid from amyotrophic lateral sclerosis patients preferentially elevates intracellular calcium and toxicity in motor neurons via AMPA/kainate receptor. J Neurol Sci 2005, 235:45-54.

Publish with Bio Med Central and every scientist can read your work free of charge

"BioMed Central will be the most significant development for disseminating the results of biomedical research in our lifetime. "

Sir Paul Nurse, Cancer Research UK

Your research papers will be:

- available free of charge to the entire biomedical community

- peer reviewed and published immediately upon acceptance

- cited in PubMed and archived on PubMed Central

- yours - you keep the copyright

Submit your manuscript here:

http://www.biomedcentral.com/info/publishing_adv.asp
BioMedcentral 